\title{
Survey of International Space Station Charging Events
}

\author{
P. D. Craven \\ NASA/Marshall Space Flight Center, MSFC, AL 35812 \\ Phone: (256) 544-7649; Email: Paul.Craven@nasa.gov \\ Kenneth H. Wright, Jr. \\ University of Alabama-Huntsville \\ Joseph I. Minow, Victoria N. Coffey, Todd A. Schneider, \\ Jason A. Vaughn, Dale C. Ferguson \\ NASA/Marshall Space Flight Center \\ Linda N. Parker \\ Jacobs Technology
}

\begin{abstract}
With the negative grounding of the $160 \mathrm{~V}$ Photovoltaic (PV) arrays, the International Space Station (ISS) can experience varied and interesting charging events. Since August 2006, there has been a multi-probe package, called the Floating Potential Measurement Unit (FPMU), available to provide redundant measurements of the floating potential of the ISS as well as the density and temperature of the local plasma environment. The FPMU has been operated during intermittent data campaigns since August 2006 and has collected over 160 days of information regarding the charging of the ISS as it has progressed in configuration from one to three PV arrays and with various additional modules such as the European Space Agency's Columbus laboratory and the Japan Aerospace Exploration Agency's Kibo laboratory. This paper summarizes the charging of the ISS and the local environmental conditions that contribute to those charging events, both as measured by the FPMU.

Index terms - spacecraft charging, plasma environment
\end{abstract}

\section{Introduction}

Charging is an important consideration for all spacecraft because of effects on equipment and possible impacts on operations. Operators of manned spacecraft have to be especially careful because of dangers to humans performing external tasks that expose them to charged surfaces. The size of the ISS and the consequences of negatively grounded high voltage photovoltaic arrays (PVA) for power generation combined with the human presence needed for construction and the expected life of the ISS, have made charging effects a concern from the beginning. Plasma Contactor Units (PCUs) were included on the ISS to avoid the effects of potential differences on the ISS.

In order to understand charging on any body as large and complex as the ISS, it is necessary to know what is encountered as conditions (e.g. solar activity) or structures change. This paper presents a survey of the charging measured by the FPMU beginning in August, 2006 when the FPMU was installed on the S1 truss of the ISS and during times when the PCUs are off. This paper is an extension of the work presented by Wright et al. [2008] and Ferguson et al. [2003]. Table 1 delineates the change in PV array and structure configuration since the FPMU began operation. 
Table 1: ISS configuration since FPMU installed

\begin{tabular}{|r|r|}
\hline Beginning Active Time & Configuration \\
\hline August 2006 & 1 PVA on Z1 truss \\
\hline December 2006 & 1 PVA port, 1/2 PVA Z1 \\
\hline June 2007 & 1 PVA port, 1 PVA starboard \\
\hline November 2007 & 2 PVA port, 1 PVA starboard \\
\hline February 2008 & ESA Columbus module \\
\hline March 2008 & Japanese Kibo module - part 1 \\
\hline June 2008 & Harmony node and Kibo part 2 \\
\hline
\end{tabular}

The FPMU is a package of four plasma instruments designed and built by Utah State University (USU) under contract to the NASA/Johnson Space Center (JSC). The FPMU was designed and built to measure the local potential of the ISS relative to the plasma and to measure the density and electron temperature of the local plasma. The four probes are: a Floating Potential Probe (FPP), a Plasma Impedance Probe (PIP), a Wide-sweep Langmuir Probe (WLP), and a Narrow-sweep Langmuir Probe (NLP) with associated electronics. The operation is autonomous with either an on or an off state. The FPMU has been described elsewhere [Swenson et al., 2003a, Swenson et al, 2003b, Swenson et al., 2005, Wright et al., 2008] but a brief description of each probe is given below. Initial FPMU on orbit results are given in Wright et al. [2008]. In this paper, we will expand on the results of Wright et al. [2008], showing the five types of charging experienced so far and under what conditions each type of charging is observed.

\section{Floating Potential Probe (FPP)}

The FPP is a gold-plated sphere of radius $5.08 \mathrm{~cm}$ and is essentially a probe of a high impedance voltmeter with the other connection referenced to ISS ground. The sphere potential is determined by local plasma conditions, and within a few $\mathrm{kT}_{\mathrm{e}}$ of the plasma potential provides a reference for measuring the potential of the ISS $(k=$ Boltzmann's constant and $\mathrm{T}_{\mathrm{e}}=$ electron temperature). Data is sampled at $128 \mathrm{~Hz}$ with $100 \mathrm{mV}$ resolution. This is the primary probe for ISS floating potential because it is a direct measurement of the floating potential.

Wide-Sweep Langmuir Probe (WLP)

The WLP is a gold-plated sphere also of radius $5.08 \mathrm{~cm}$. The voltage applied to the probe is swept from $-20 \mathrm{~V}$ to $80 \mathrm{~V}$ relative to chassis ground (ISS structure) and the resulting currents to the probe are measured. Sweeps are accomplished each second, with the potential sweeping from low to high voltage in one second and back down from high to low in the next second. The sweep is comprised of three parts as described by Wright et al. [2008] and references therein. Step sizes of $50 \mathrm{mV}$ from $0 \mathrm{~V}$ to $50 \mathrm{~V}$ provide sufficient resolution for a determination of $T_{e}$ (which requires several samples in the electron retarding portion of the sweep). The floating potential can be obtained over the full $-20 \mathrm{~V}$ to $80 \mathrm{~V}$ range, within an 
uncertainty of $+/-2 \mathrm{~V}$. The WLP is the primary probe for densities because its wide voltage sweep allows complete coverage of the ion and electron saturation regions.

\section{Narrow-Sweep Langmuir Probe (NLP)}

The NLP is a guarded gold-plated cylinder with collector dimension of radius $1.43 \mathrm{~cm}$ and length $5.08 \mathrm{~cm}$. The NLP is placed mid-way on the boom supporting the FPP. A sweep from $-4.9 \mathrm{~V}$ to $+4.9 \mathrm{~V}$, in steps of $\sim 12 \mathrm{mV}$, is applied to the NLP during one second, followed by a sweep down from $4.9 \mathrm{~V}$ to $-4.9 \mathrm{~V}$ in the next second. This sweep voltage is referenced to the floating potential measured by the FPP. In this way, the electron and ion retarding regions of the plasma current-voltage profile are seen, as the region sampled will move through the $-180 \mathrm{~V}$ to $+180 \mathrm{~V}$ range of the FPP. This configuration allows the density and electron temperature to be determined at $1 \mathrm{~Hz}$. Temperatures from this probe are considered as the definitive temperatures relative to those from the WLP because of the smaller step size and because of a suspected change to the work function of the WLP sphere surface.

\section{Plasma Impedance Probe (PIP)}

The PIP consists of a short dipole antenna electrically isolated from the ISS. The PIP measures the electrical impedance (magnitude and phase) of the antenna at 256 frequencies over a $100 \mathrm{KHz}$ to $20 \mathrm{MHz}$ range. Electron density, electron-neutral collision frequency, and magnetic field strength can potentially be deduced from these impedance measurements. More detailed discussion of the PIP and data reduction from it can be found in Wright et al [2008] and Coffey et al [2008].

\section{Discussion}

\section{Data Source}

Floating potentials at the location of the FPMU on the ISS are given directly by the FPP. Floating potential, plasma number density and electron temperature from the WLP and NLP are determined as described by Wright et al. [2008] and references therein. Although we do not repeat that discussion here, the data handling and analysis is essentially the same and is used to generate the plasma density and temperature shown in this paper. For the charging events described here, the FPP is the primary source of spacecraft floating potential (potential relative to the ambient plasma) values, the WLP is primary for plasma density, and the NLP is primary for electron temperature.

\section{Data Presented}

A survey of the charging events that have been detected on the ISS in the time between August 2006 and November, 2008 has been performed and notable examples are presented in this paper. During this time period, the solar cycle is in the trailing minimum of cycle 23 and throughout the FPMU coverage the geomagnetic activity is low $(\mathrm{Kp}<3)$ with rare periods of higher geomagnetic activity $(\mathrm{Kp}>4)$. Table 2 shows the number of FPMU operating days in each year that total to 167 days. The coverage in each of these years is not uniform and is grouped into campaigns that usually cover only several days at a time. The breakout of FPMU operation days for each year are: 2006 - 6 days, $2007-42$ days, and $2008-119$ days. In Fig. 1 the mean altitude of the ISS during 
each FPMU operation day is shown together with the occurrence and duration of the number of PV arrays. The reference start time in Fig. 1 is GMT day 2006/216 - the first full day of FPMU operation.

Table 2: Operation dates for FPMU

\begin{tabular}{|c|c|c|}
\hline Year & Approx. GMT Duration & Calendar Days \\
\hline 2006 & 215/22:30 - 220/14:30 & Aug 3 - 8 \\
\hline \multirow[t]{11}{*}{2007} & 022/19:15 - 031/00:00 & Jan $22-30$ \\
\hline & 060/12:00 - 063/00:00 & Mar $1-3$ \\
\hline & $103 / 12: 00-104 / 12: 00$ & Apr $13-14$ \\
\hline & $123 / 00: 23-124 / 00: 00$ & May 3 \\
\hline & 165/10:23 - 169/04:00 & Jun 14 - 18 \\
\hline & 187/03:47 - 191/00:00 & Jul 6 - 9 \\
\hline & $253 / 13: 00-257 / 03: 00$ & Sep $10-14$ \\
\hline & 301/18:10 - 307/02:00 & Oct 28 - Nov 3 \\
\hline & $312 / 05: 52$ - 312/10:33 & Nov 8 \\
\hline & $324 / 22: 35-327 / 19: 05$ & Nov $20-23$ \\
\hline & $354 / 14: 56-355 / 23: 53$ & Dec 20 - 21 \\
\hline \multirow[t]{15}{*}{2008} & 022/23:48 - 037/16:00 & Jan 22 - Feb 6 \\
\hline & $067 / 16: 57-074 / 22: 28$ & Mar 7 - 14 \\
\hline & 086/00:00 - 088/23:57 & Mar 26 - 28 \\
\hline & 099/13:30 - 101/09:32 & Apr $8-10$ \\
\hline & $126 / 23: 42-131 / 01: 05$ & May $5-10$ \\
\hline & 141/01:06 - 153/23:52 & May 20 - Jun 1 \\
\hline & 170/23:50 - 173/05:00 & Jun 18 - 21 \\
\hline & 189/00:00 - 203/00:00 & Jul $7-20$ \\
\hline & 225/00:14 - 229/00:30 & Aug $12-16$ \\
\hline & $232 / 00: 26-236 / 23: 54$ & Aug $19-23$ \\
\hline & 238/23:45 - 243/00:01 & Aug $25-30$ \\
\hline & 248/14:06 - 250/00:02 & Sep $4-6$ \\
\hline & $253 / 00: 03-255 / 06: 44$ & Sep $9-11$ \\
\hline & 269/18:37 - 269/23:31 & Sep 25 \\
\hline & $276 / 23: 24-309 / 17: 53$ & Oct 2 - Nov 4 \\
\hline
\end{tabular}

As noted earlier in Table 1, several external configuration changes have been made to the ISS between August, 2006 and November, 2008 - the most notable of which are the relocation and addition of the PV arrays and the addition of the European, US, and Japanese modules. In the November 2008 configuration, there are two PV arrays on the port end and one on the starboard end of the ISS truss. One additional array will be added to the starboard end in early 2009. Although other attitudes have been used, the FPMU data shown in this paper were taken with the ISS in the +XVV attitude (the X-axis is parallel to the US and Russian pressurized elements and along the velocity direction). 
The orbit period is such that all latitudes between plus and minus 51.7 deg are covered twice in an orbit but at different longitudes and different times relative to the sun. There are usually two day/night crossings per orbit with the ratio of day to night depending on the orientation of the orbit relative to the sun, i.e., beta angle.. At beta angles whose magnitude is $\geq\left|72^{\circ}\right|$, no night-time occurs

\section{Charging Types}

Five categories of charging are seen with the FPMU on the ISS. Each category of charging is the result of the interaction of the ISS structure either with the magnetic field, the PV array operation, geophysical conditions, or operations on the ISS. Superposition applies to potentials, so that several acting simultaneously will result in a higher total potential than when acting alone.

The five types of charging events are:

\section{Magnetic Induction}

Magnetic induction charging is always present and is the result of the ISS moving relative to the Earth's magnetic field. Figure 2 shows an example of the FPMU measured floating potential (top panel) at each second (average of the 128 FPP samples obtained in one second), as a function of time on April 8, 2008 (GMT 2008/099). Note that although the ISS charges negatively with respect to the ambient plasma, for convenience the potentials are plotted as positive in this and subsequent figures. Plasma density and temperature are plotted in the middle and bottom panel, respectively, for comparison. Magnetic induction charging shows a sinusoidal-like character. This is a well explained behavior of spacecraft potentials [Whipple, 1981; Barsamian et al., 2003; Mikatarian et., 2004; Ferguson, 2004; Reddell et al., 2006], is always present throughout the ISS orbit, and is dependent on the velocity of the ISS, the earth's magnetic field, and the position of the FPMU on the truss through the relation $\mathrm{V}_{\text {ISS }} \mathrm{xB} \cdot \mathrm{L}$, where $\mathrm{V}_{\text {ISS }}$ is the ISS velocity, $\mathrm{B}$ is the local magnetic field strength, and $\mathrm{L}$ is a position vector to the FPMU. With the ISS in $+\mathrm{XVV}$ attitude, the potential at the FPMU location is largest at the higher northern latitudes and smallest at the higher southern latitudes where the high $\mathrm{V}_{\text {ISs }} \mathrm{XB} \cdot \mathrm{L}$ potential is on the end of the truss opposite the position of the FPMU. Potentials from other types of charging ride on top of the potentials resulting from $\mathrm{V}_{\mathrm{ISS}} \mathrm{xB}$ charging.

\section{Equatorial}

Also seen in Fig. 2 is a local potential enhancement in the equatorial region that is coincident with the Appleton anomaly location. This event is associated with favorable plasma conditions for charging; namely, an increased plasma density and a decreased plasma temperature. The two changes together are associated with an increase in the rate of electron capture by the PV arrays [Ferguson et al. 2003; Ferguson and Morton, 2001]. Passage through the Appleton anomaly occurs at or near local noon. With the PVAs in sun tracking mode, the array attitude is away from the ram-facing position and results in only a few volts change in floating potential above the magnetic induction background. 


\section{High latitude (Auroral)}

Figure 3 shows a nighttime charging event occurring on GMT 2008/086/07:57:45 at high magnetic latitudes $\left(59.2^{\circ}\right)$ near midnight $(0.14 \mathrm{MLT})$. An expanded view of the high-resolution floating potential is presented in Fig. 4. Charging is variable throughout the minute represented by this trace. It appears that the region of increased density from about 07:57GMT to 07:59GMT may coincide with a region of precipitating electrons as determined from the JHU/APL Ovation web site (URL: http://sdwww.jhuapl.edu/Aurora/ovation/). The electron number flux from the JHU/APL model is shown in Fig. 5 as a function of geographic latitude and longitude. The path of the ISS is shown by the curve entering at the top center and exiting at the left center. Number flux is color coded as shown in color bar in the figure. The final floating potential is determined by a balance between the increased electron collection and secondary emission resulting from energetic electrons.

\section{Unusual events}

In February 2008 the ESA-built Columbus module was integrated to the ISS. Included on the Columbus module is a Plasma Electron Gun Payload (PLEGPAY) that uses a hollow cathode for plasma generation (see Matticari et al., 2001 for description of hardware). Figure 6 shows the ISS floating potential during a time period when PLEGPAY performed operations to determine the I-V characteristics of the device. When PLEGPAY reached its highest emission current, the ISS floating potential at the FPMU location was driven to $+25 \mathrm{~V}$. Coordinated, systematic observations between the FPMU and PLEGPAY are likely to be conducted in the future.

\section{Eclipse exit}

When the PCUs are not operating, charging is always observed in the transition from eclipse to daylight. Eclipse exit charging events are characterized by transient increases in the negative potential upon entering sunlight with little or no change in potential observed in darkness immediately before the terminator crossing. Examples of these events have been presented in a number of studies [Mandell et al., 2003; Barsamian et al., 2003]. The duration of the rise and fall times of the eclipse exit charging events define two types of eclipse exit charging - normal charging event (NCE) and rapid charging event (RCE). These are two, apparently distinct charging phenomenon.

\section{i. Normal Charging Event (NCE)}

In an NCE, the rise time, the time for the potential to go from background to maximum, is on the order of $10 \mathrm{~s}$ of seconds. The trailing edge, the time from maximum to the background level (i.e the $\mathrm{VxB}$ level) can last for several minutes governed at first by the $\mathrm{PV}$ array power management and then by the plasma environment properties and the angle of the PV array normal to ram. An example of an NCE from GMT 2008/279 is presented in Fig. 7. Also shown in Fig. 7 are the currents drawn from each wing of the three PV arrays. The leading edge of the potential change in Figure 7 shows multiple time scales, a characteristic of these normal charging events, and follows the PV array rise to full voltage and current. The trailing edge shows that the ISS potential is slowly adjusting while the arrays current is constant. As the array current, either through power 
management or because of pointing position decreases, the rate of change of the ISS potential decreases, following the decrease in the current from the PV arrays, i.e. the number of active strings in the arrays.

\section{ii. Rapid Charging Event (RCE)}

The RCEs are found to occur at eclipse exit and are characterized by a faster leading and trailing edges as compared to an NCE. RCE leading edge rise times are $<10$ seconds with most lying in the range of 2-5 seconds. The RCE trailing edge of the potential decays to the background in times ranging from 10-30 seconds. The RCEs have occurred in 44 days of FPMU operation with multiple occurrences on some days to give a total of more than 80 events observed to date. The largest amplitude RCE detected is shown in Fig.8. This event occurred on July 7, 2007 near the equator during a local plasma density depletion at a value of $1.4 \times 10^{10} \mathrm{~m}^{-3}$. Also included in Fig. 8 is the PV array current data. The initial decay of the potential does not seem to be correlated with the PV array activity but a "knee" is observed in the trailing edge at the same time the array current reach a static value. A "knee" feature is common to almost all of the RCEs.

Sufficient conditions for the occurrence of a rapid charging event are eclipse exit with a plasma density $<3.5 \times 10^{10} \mathrm{~m}^{-3}$. These densities occur in local plasma depletions that are found to reside at the higher geographic latitudes ( $\mid$ latitude $\mid \geq 37^{\circ}$ ) and in the equatorial regions ( $\mid$ latitude $\mid \leq 17^{\circ}$ ). The geographic latitude occurrence and the amplitude of the RCEs are shown in Fig. 9. It is well known that local plasma depletions (bubbles, etc.) tend to occur at the latitudes where the RCEs have been detected. Figure 10 shows the dependence on the amplitude of the RCE with plasma density. The trend is increasing amplitude with decreasing density but the data have a lot of scatter. However, there is a clearly defined upper limit to the charging. It has been observed that if the plasma density is low enough at eclipse exit, the rapid event does not always occur and, if it occurs, the maximum charging value is not always achieved. Since all of the data is not ordered along the "red curve", this indicates additional parameter(s) influence the RCEs. Determination of the physical explanation as to the duration and amplitude the rapid charging event is ongoing.

\section{Summary}

A survey of charging events on the ISS, based on a database of over 160 days of FPMU operation on the ISS, has been performed. The history of maximum floating potential per day as observed by the FPMU is presented in Fig. 11. Only data from days where at least 6 hours of FPMU data were obtained and no PCU operation were considered. The RCE data are separated from the other charging data. On each day where a RCE occurred, the potential value of the maximum amplitude RCE is shown in Fig. 11 (see the red and blue circles). For the other common charging data, namely magnetic induction and the NCE, using data from the northern hemisphere events is the best way to show the maximum values. Recall that with the FPMU mounted on the starboard side and the $+\mathrm{XVV}$ flight attitude, the floating potential will show a maximum value in the northern hemisphere either at the peak of the magnetic induction or the peak 
of an NCE. All days where eclipse exit occurred in the northern hemisphere are represented by black circles in Fig. 11.

The data span the ISS configurations listed in Table 1 - notably PV array configurations of one, one and half, two, and three PV arrays. All the events above magnitude $35 \mathrm{~V}$ are the RCE type. It is tempting to say that increased PV array area contributes to the occurrence of the RCE but the disparity in sampling between pre-2008 and during 2008 prevents any meaningful statement. The NCE/ $\mathrm{V}_{\text {ISS }} \times \mathrm{B} \cdot \mathrm{L}$ events reached an $\sim 32 \mathrm{~V}$ limit and the limit has stayed fairly constant over time as the PV array area has doubled from early 2007 to late 2008. Reasons for this include: (1) the starboard array has not fully tracked the sun due to the malfunctioning Solar Array Rotating Joint (SARJ); (2) solar activity has been in an extended minimum; and (3) the ISS is at a higher mean altitude in 2008 than in 2007 (see Fig. 1). Regarding item (2), instruments aboard the Communication/Navigation Outage Forecast System (C/NOFS) spacecraft that was launched in April 2008 are showing that the ionosphere is at historic low altitudes since the space program began (http://www.nasa.gov/topics/earth/features/outer_atmosphere.html 12/15/2008 press release from GSFC). The implications of items (2) and (3) are that the ionospheric F2 density maximum has been at altitudes much lower than the ISS and, in general, as one increases in altitude in the top-side ionosphere, the density decreases and the night-time electron temperature increases. These changes to the plasma environment are in the direction toward lower electron collection at eclipse exit for the PV arrays.

Our survey shows that the charging can be catalogued into five distinct types. Magnetic induction charging ( $\mathrm{V}_{\text {ISS }} \times \mathrm{B} \cdot \mathrm{L}$ ) has been previously reported [Ferguson et al., 2001, Barsamian et al., 2003; Mikatarian et al.,2004; Ferguson, 2004; Reddell et al., 2006]. Eclipse exit has also been recognized as an area where charging is likely to be maximized [Alred et al., 2006; Reddell et al., 2006] and this is seen in our normal eclipse charging as well as in data previously obtained on the ISS by the Glenn Research Center Floating Potential Probe in 2001 [Ferguson et al. 2001; Barsamian et al., 2003]. Three apparently new categories can be added based on this survey: equatorial, high latitude night-time, and rapid eclipse exit charging. The equatorial charging events are due to the lower electron temperatures as apparently are the high latitude nighttime charging events even though they may be occurring in an area of precipitating energetic electrons. Both need to be investigated further to better define the relation between their occurrence and local conditions. The FPMU obtains plasma measurements at $1 \mathrm{~Hz}$ and the floating potential measurements at $128 \mathrm{~Hz}$. This high time resolution allows all of the charging events to be observed, and, evidently, discovery of a new charging category - the rapid charging event. We anticipate obtaining better knowledge on dependence of all types of charging on geophysical conditions (solar activity, geomagnetic activity), configuration (modules and the full complement of solar arrays), and operation of instruments by the international partners on the ISS.

\section{Acknowledgements}

We thank JHU/APL and the Ovation project for providing on-line access to the auroral oval models. 


\section{References}

J. Alred, R. Mikatarian, and S. Koontz, "Impact of Solar Array Position on ISS Vehicle Charging", 2006, $44^{\text {th }}$ AIAA Aerospace Sciences Meeting and Exhibit, Reno, NV, Jan. 921, AIAA paper \# 2006-868.

H. Barsamian, R. Mikatarian, J. Alred, J. Minow, and S. Koontz, "ISS Plasma Interaction: Measurements and Modeling," $8^{\text {th }}$ Spacecraft Charging Technology Conference, Huntsville, AL, Oct. 20-24, 2003, NASA/CP-2004-213091.

V. N. Coffey, K. H. Wright, Jr., J. I. Minow, T. A. Schneider, J. A. Vaughn, P. D. Craven, M. O. Chandler, S. L. Koontz, L. N. Parker, and T. H. Bui, "Validation of the Plasma Densities and Temperatures From the ISS Floating Potential Measurement Unit," IEEE Trans. Plasma Science, Plasma Science, Vol. 36, Issue 5, Part 2, pp. 2301- 2308, 2008.

D. C. Ferguson, T. L. Morton, and G. B. Hillard, "First Results from the Floating Potential Probe (FPP) on the International Space Station," 39th AIAA Aerospace Sciences Meeting Exhibit, Reno, NV, Jan. 9-11, 2001, AIAA paper \# 2001-0402.

D.C. Ferguson, G. B. Hillard, T. L. Morton, and R. Personen, "ISS FPP Ionospheric Electron Density and Temperature Measurements - Results, Comparison with the IRI-90 Model, and Implications for ISS Charging", $41^{\text {st }}$ AIAA Aerospace Sciences Meeting and Exhibit, Reno, NV, Jan. 6-9, 2003, AIAA paper \# 2003-1083.

D. C. Ferguson, "VxB effects on Space Station," $2^{\text {nd }}$ International Energy Conversion Engineering Conference, Providence, RI, Aug. 16-19, 2004, AIAA paper \#2004-5669.

R. Mikatarian, H. Barsamian, J. Alred, J. Kern, J. Minow, and S. Koontz, "Electrical Charging of the International Space Station," $41^{\text {st }}$ AIAA Aerospace Sciences Meeting and Exhibit, Reno, NV, Jan. 6-9, 2003, AIAA paper \# 2003-1079.

M. J. Mandell, V. A. Davis, B. Gardner, and G. Jongeward, "Electron collection by International Space Station solar arrays," $8{ }^{\text {th }}$ Spacecraft Charging Technology Conference, Huntsville, AL, Oct. 20-24 2003, NASA/CP-2004-213091.

G. Matticari, M. Materassi, G.E. Noci, A. Severi, and J. Sabbagh, "PLEGPAY: Plasma Contactor Experiment on the International Space Station", $27^{\text {th }}$ International Electric Propulsion Conference, Pasadena, CA, Oct. 15-19, 2001, IEPC-01-261.

B. Reddell, J. Alred, L. Kramer, R. Mikatarian, J. Minow, and S. Koontz, "Analysis of ISS Plasma Interaction," AIAA-2006-0865, $44^{\text {th }}$ AIAA Aerospace Sciences Meeting and Exhibit, Reno, NV, Jan. 9-12, 2006, AIAA paper \# 2006-865. 
C. M. Swenson, D. Thompson, and C. Fish, "The Floating Potential Measurement Unit," $41^{\text {st }}$ AIAA Aerospace Sciences Meeting and Exhibit, Reno, NV, Jan. 6-9, 2003, AIAA paper \# 2003-1081.

C. M. Swenson, C. Fish, and D. Thompson, "Calibrating the Floating Potential Measurement Unit," ${ }^{\text {th }}$ Spacecraft Charging Technology Conference, Oct. 20-24, 2003, Huntsville, AL, NASA/CP-2004-213091.

C. M. Swenson, D. Thompson, and C. Fish, "The ISS Floating Potential Measurement Unit," $9^{\text {th }}$ Spacecraft Charging Technology Conference, April 4-8, 2005, Tsukuba, Japan.

E.C. Whipple, "Potentials of surfaces in space," Rep. Prog. Phys., Vol. 44, pp. $1197-$ $1250,1981$.

K. H. Wright, Jr., C. M. Swenson, D. C. Thompson, A. Barjatya, S. L. Koontz, T. A. Schneider, J. A. Vaughn, J. I. Minow, P. D. Craven, V. N. Coffey, L. N. Parker, and T. Bui, "Charging of the International Space Station as Observed by the Floating Potential Measurement Unit: Initial Results," IEEE Trans. Plasma Science, Vol. 36, Issue 5, Part 2, pp. $2280-2293,2008$.

Figures 


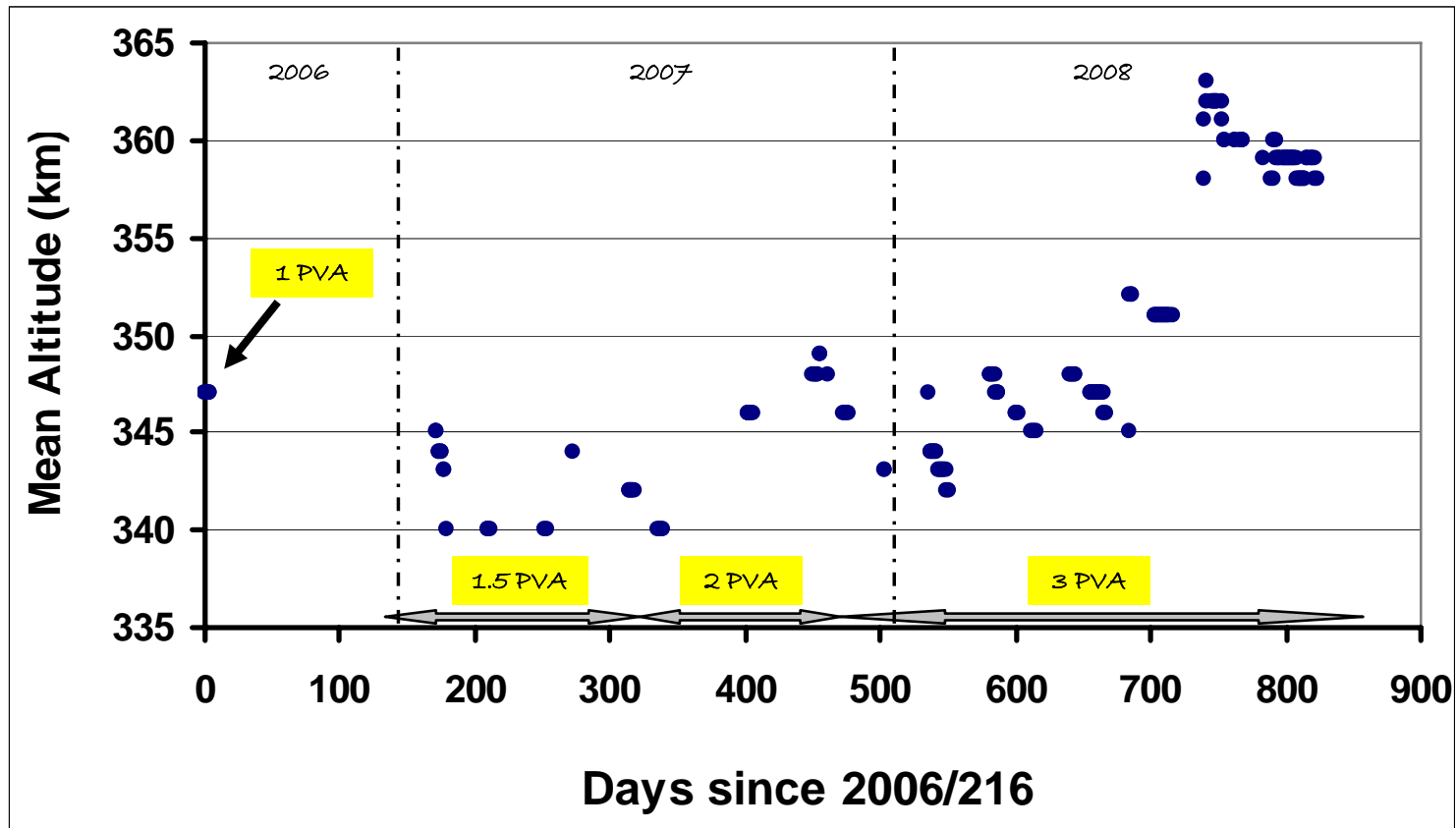

Figure 1: Mean ISS altitude for each FPMU operating day. The occurrence and duration of the PV array configurations are also noted.

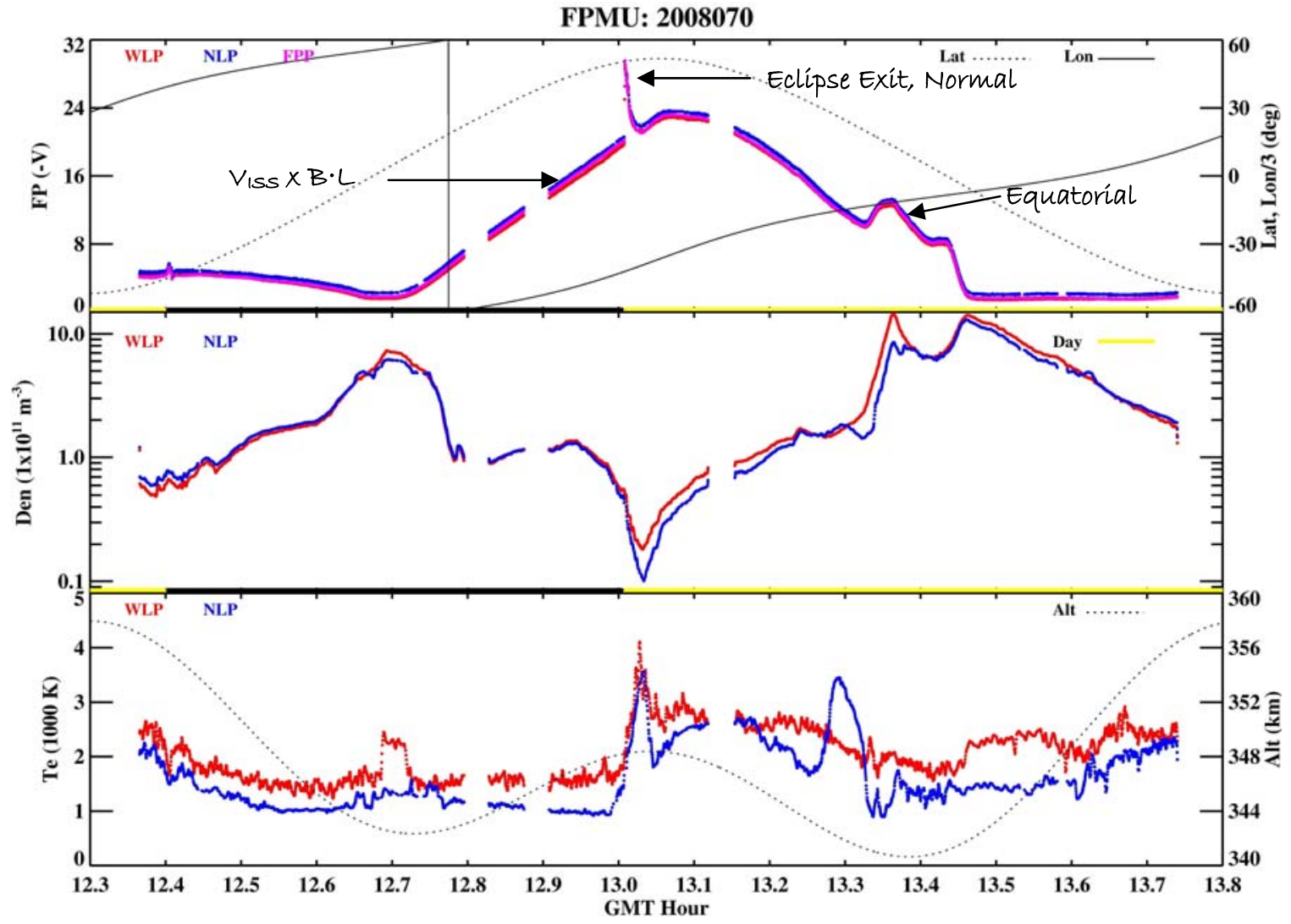

Figure 2: $\mathrm{V}_{\text {ISS }} \mathrm{xB} \cdot \mathrm{L}$, Equatorial (Appleton anomaly), and Eclipse Exit charging. 


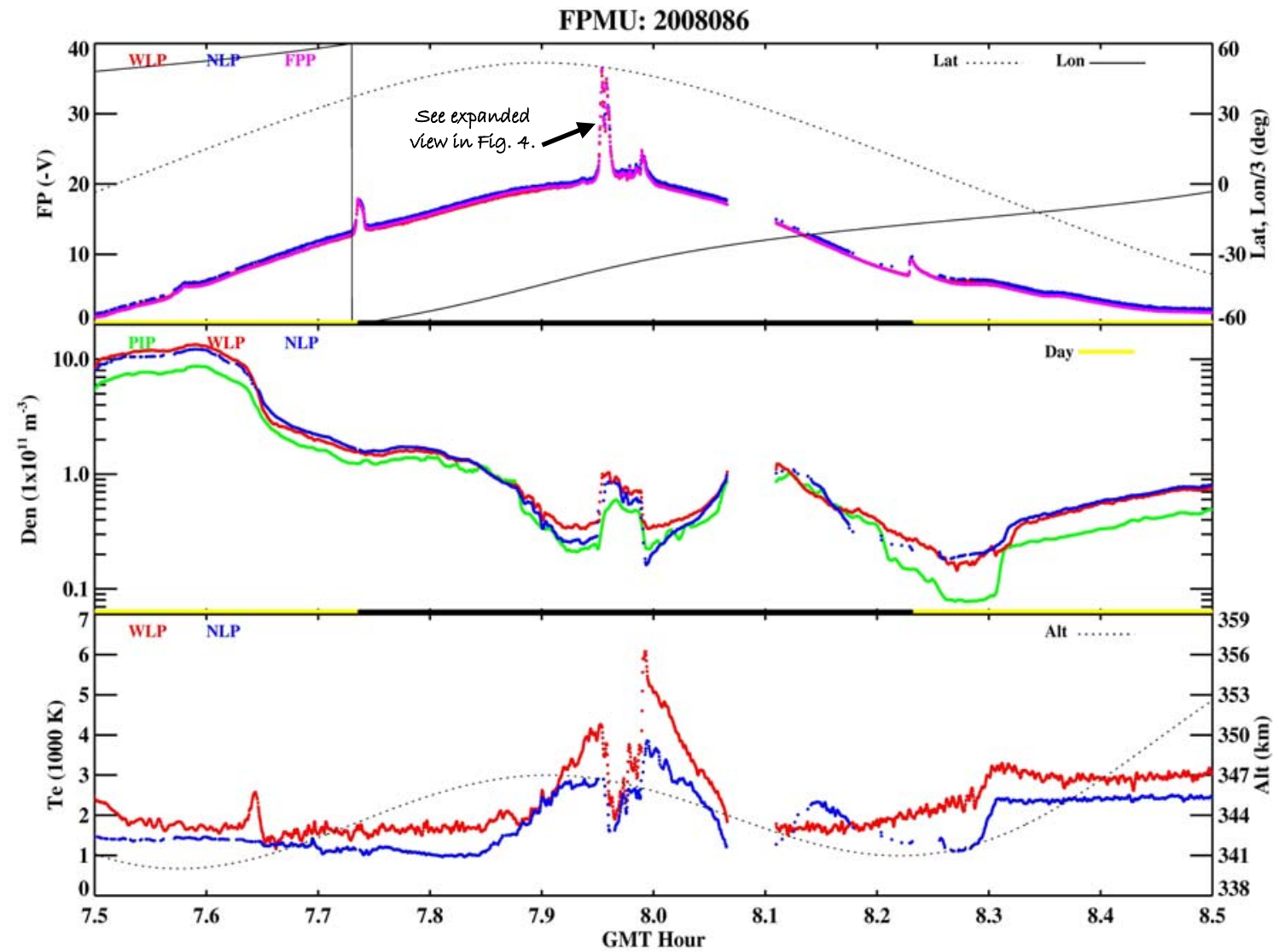

Figure 3: Example of high latitude night time charging from March 26, 2008 (GMT 2008/086).

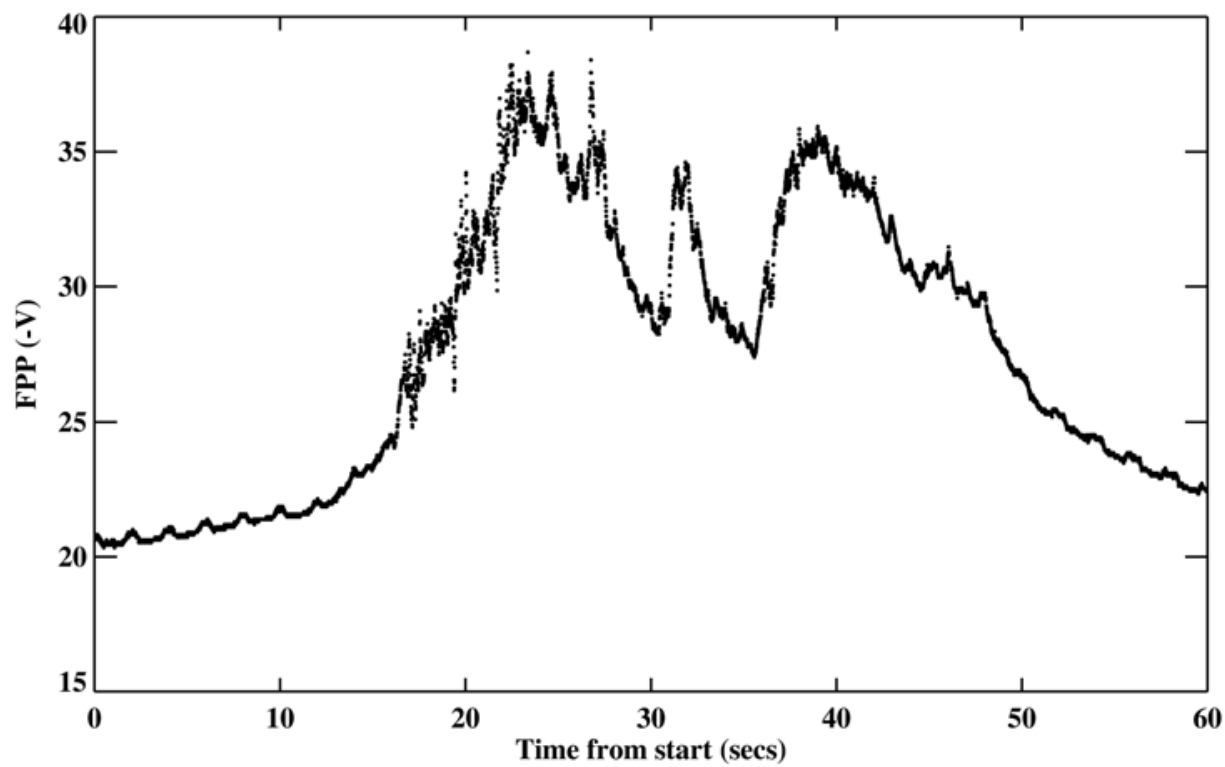

Figure 4: High resolution FPP data for GMT 2008/086/07:56:50 - 07:57:50. The small oscillation occurring between 0 to 10 seconds corresponds to the 2 -second cadence of $+80 \mathrm{~V}$ on the WLP. 


\section{NORTH CAP}

End Time 26 Mar 2008 - 07:57

No DMSP Satellite Data for this period

No UVI Data for this period.

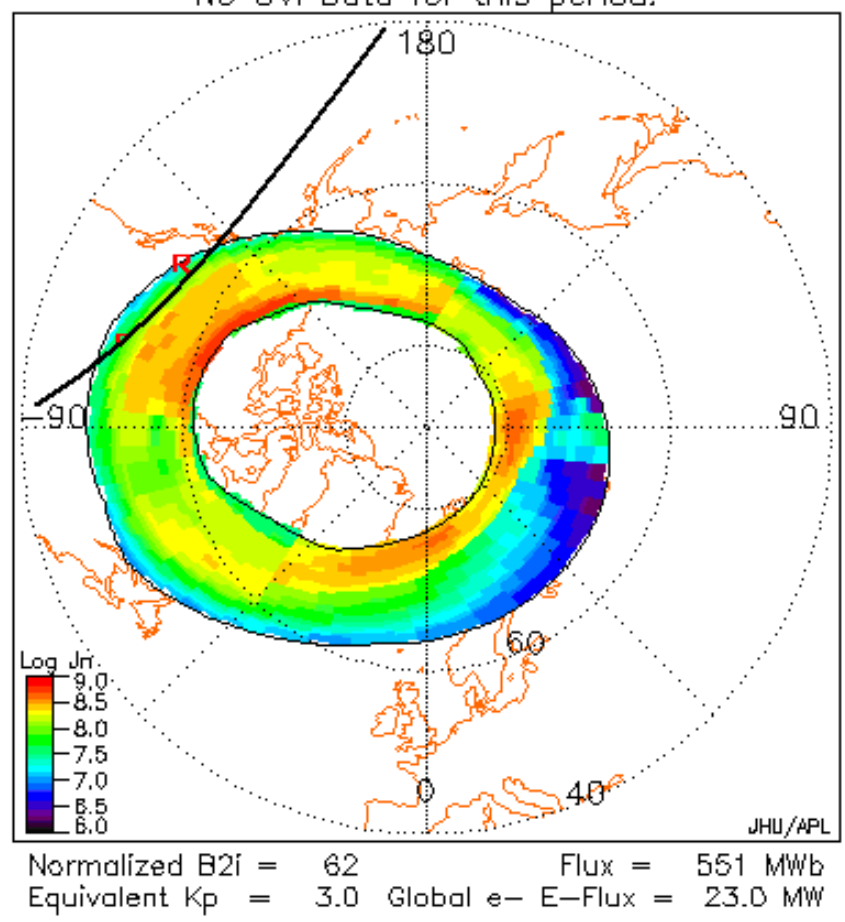

Figure 5: JHU/APL model of precipitating energetic electrons for the high latitude night time charging shown in Figs. 3 and 4. 


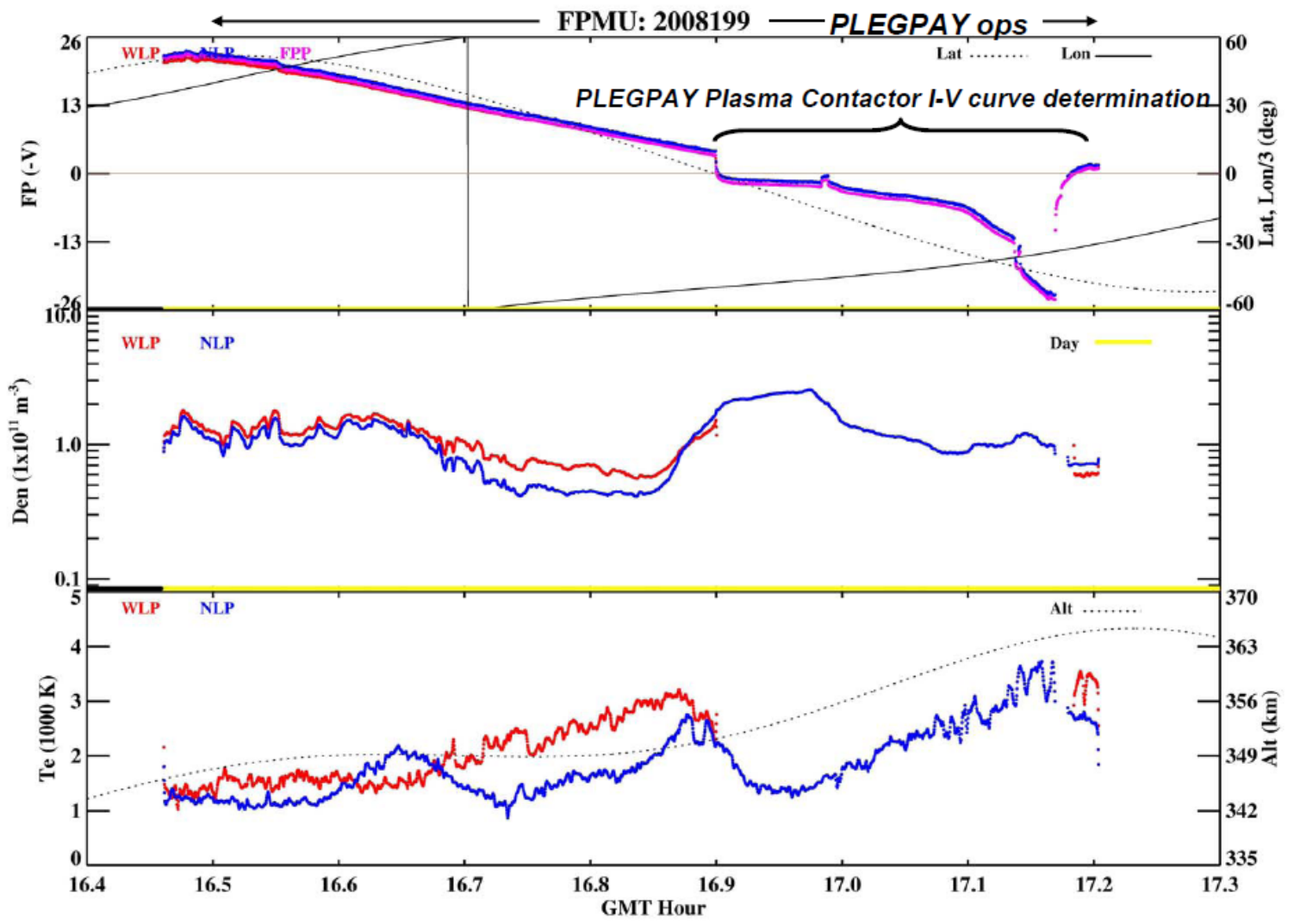

Figure 6: Impact of PLEGPAY operation on ISS charging from July 17, 2008. Note: The WLP data are not shown during the times of positive ISS floating potential because the voltage step-size during the electron saturation portion of the I-V curve has increased to $\sim 0.25 \mathrm{~V}$ and greatly impacts the accuracy of the Te measurement. 


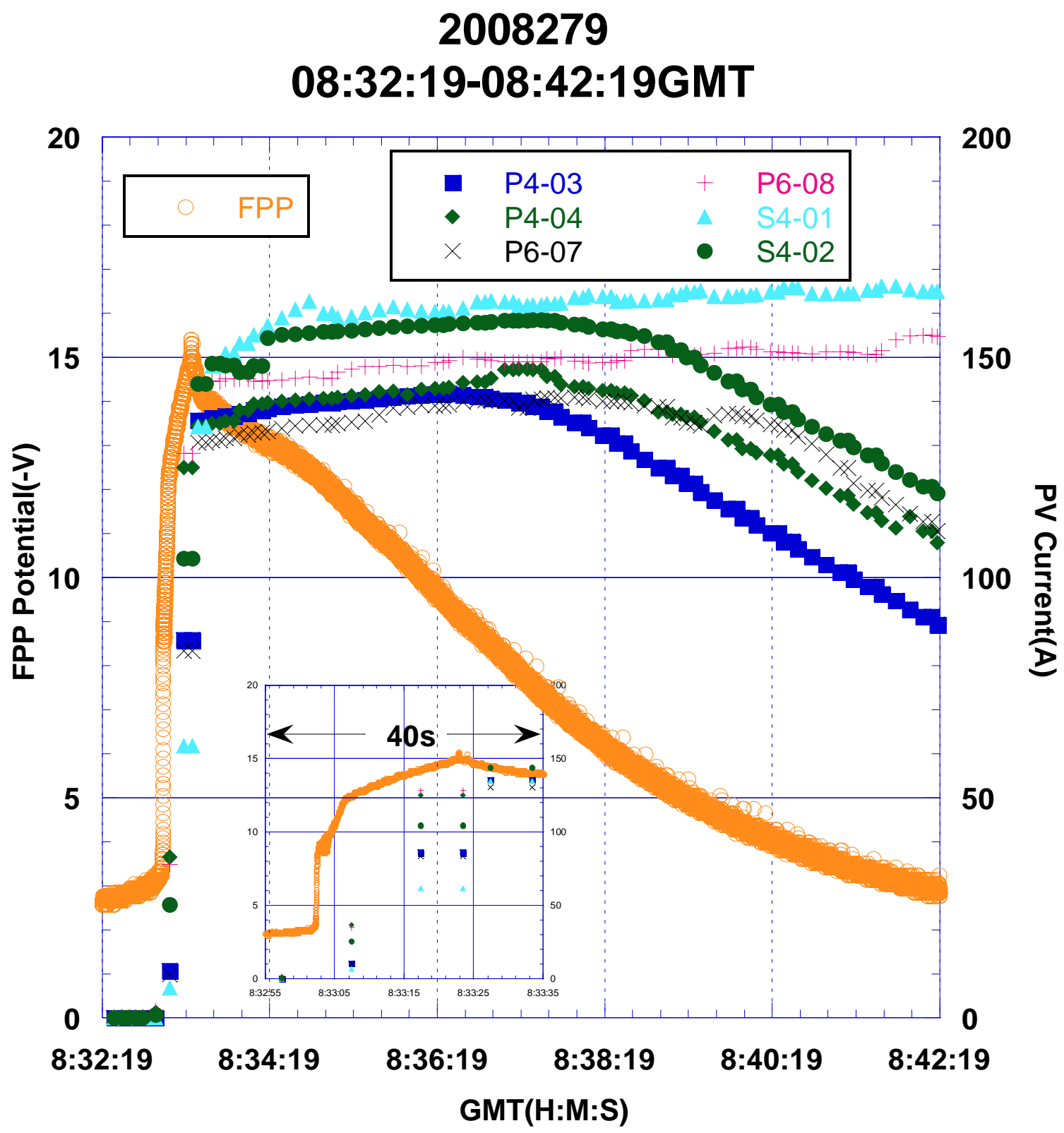

Figure 7: An example of a normal eclipse exit charging event plotted with PV array current from each of the three arrays. The FPP values are plotted on the left hand axis and the PV array current is plotted on the right hand axis. An expanded view of the rising edge is shown in the inset. Array current is denoted PX-XX or SX-XX in the legend. 


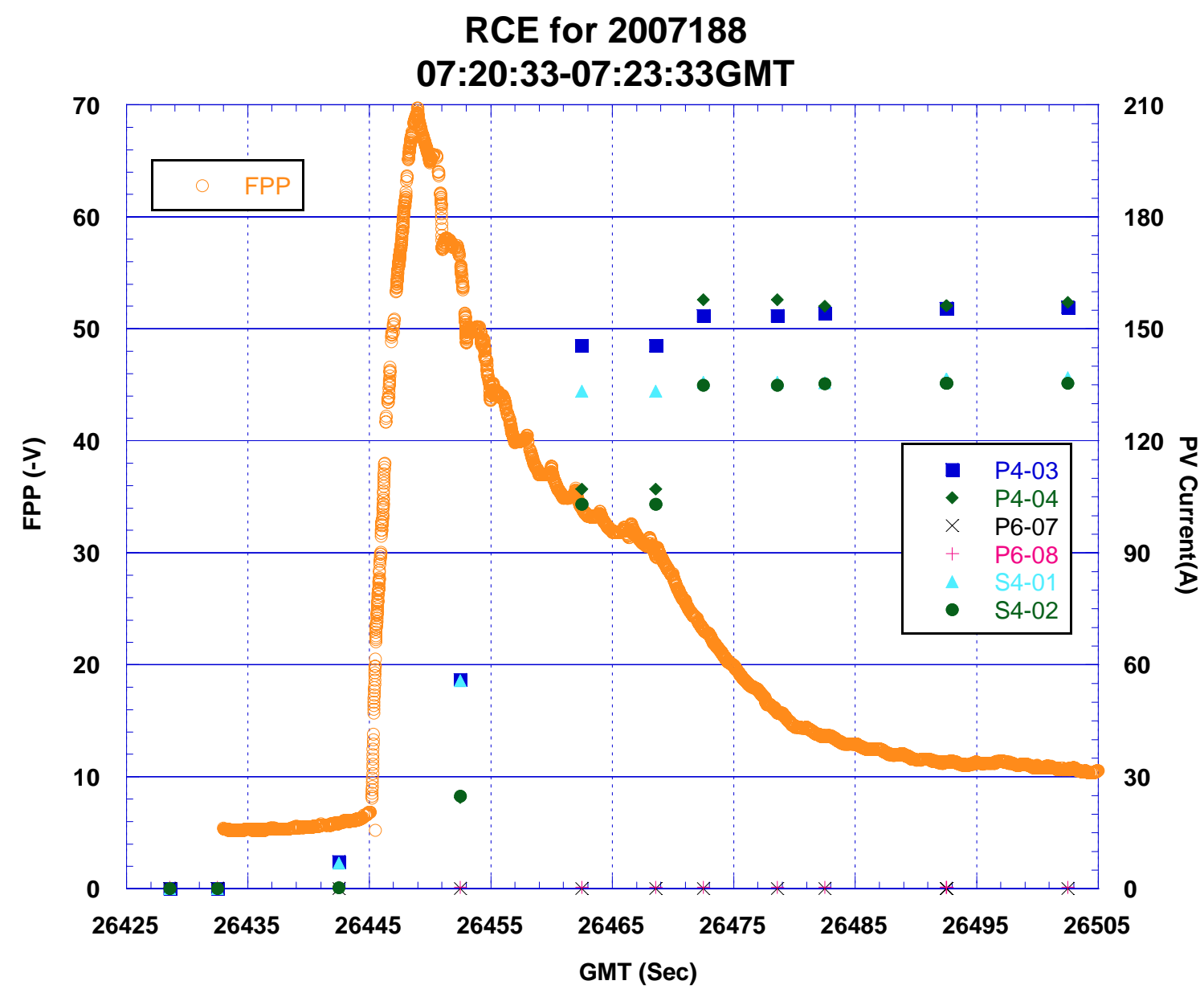

Figure 8: Rapid charging event from 2007/188 compared with PV array current data. This is the maximum RCE observed to date. The FPP values are plotted on the left hand axis and the PV array currents on the right. Array designations are the same as in Figure 7. 


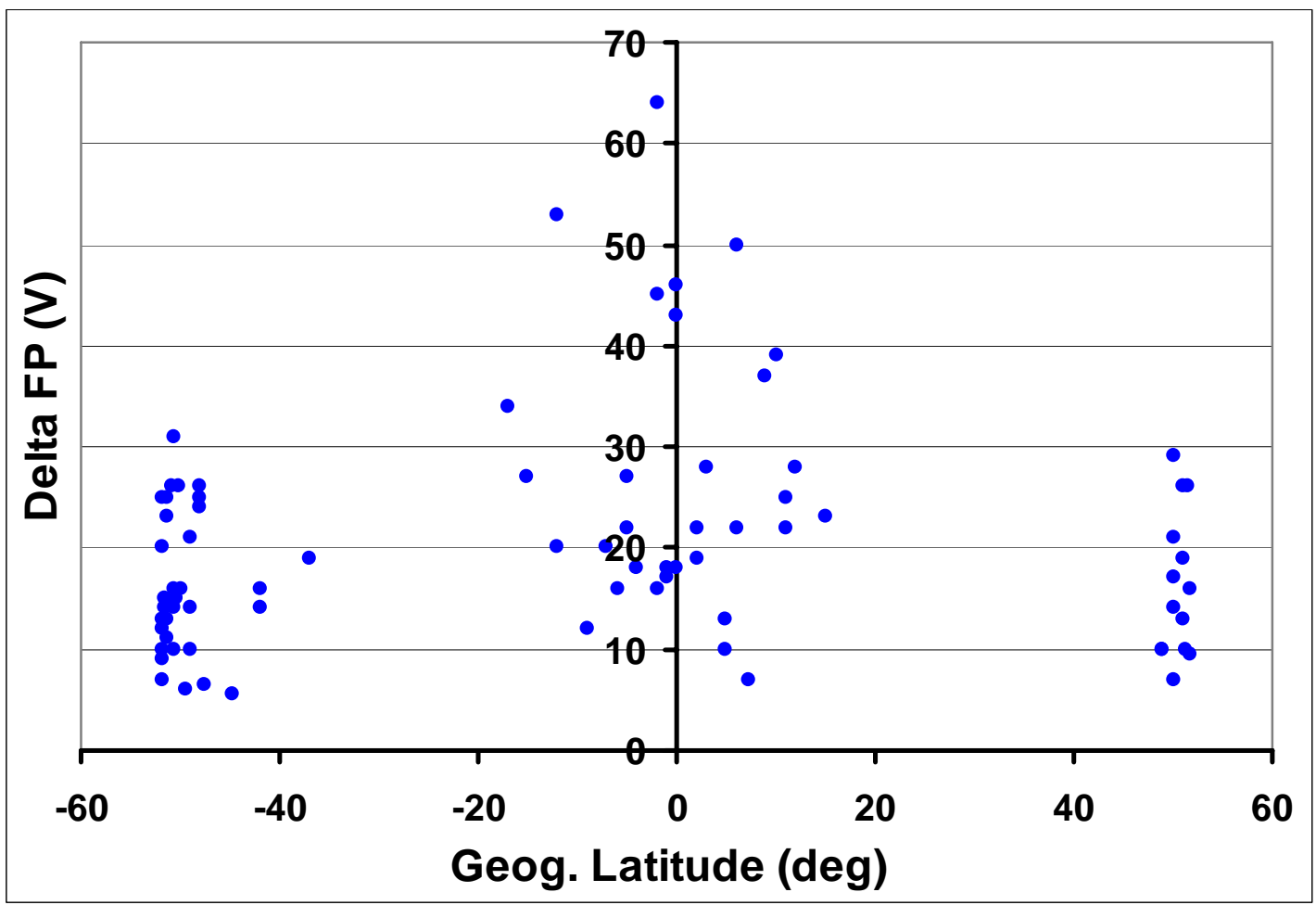

Figure 9: Geographic latitude locations of the Rapid Charging Events and their amplitude (above the magnetic induction baseline).

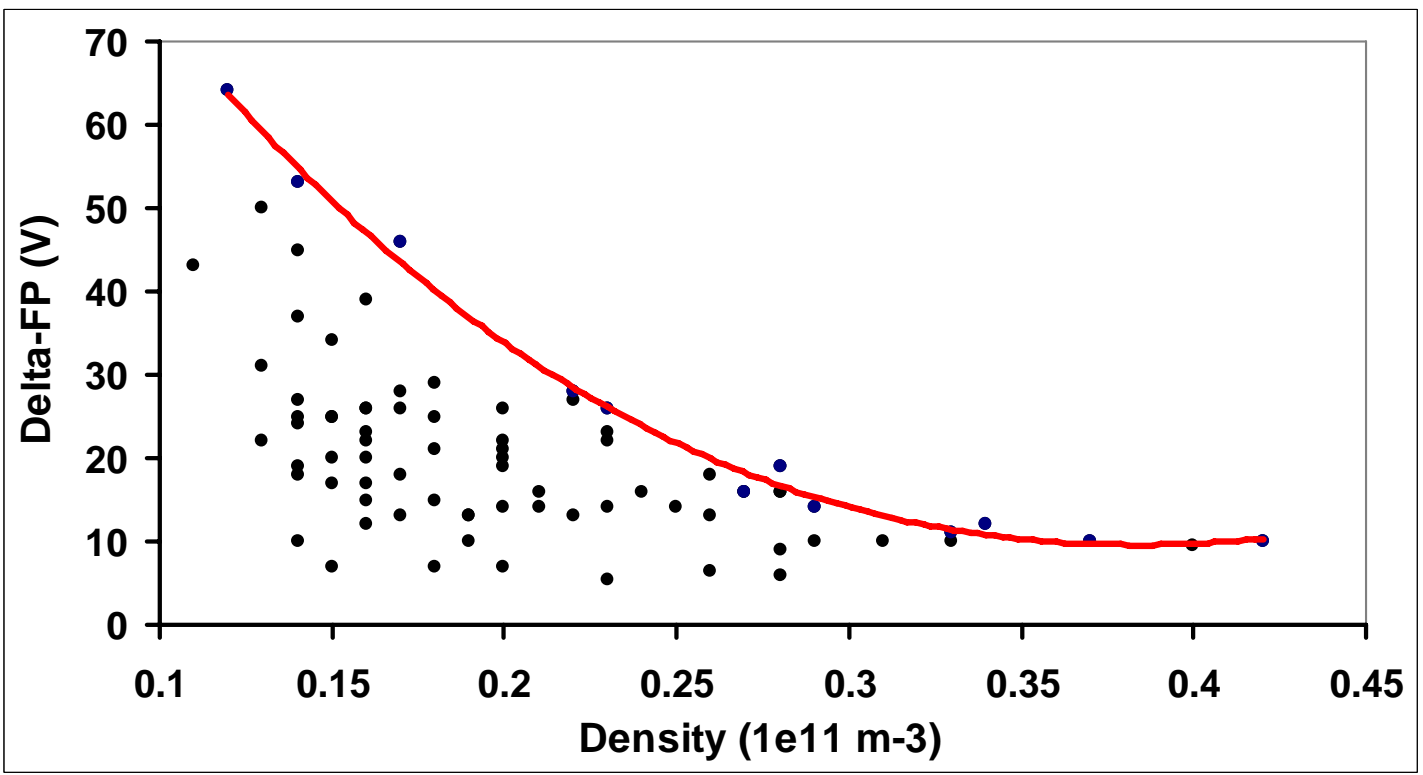

Figure 10: Variation of rapid charging event voltage amplitude (minus magnetic induction baseline) with plasma density. The red-line showing the upper limit is a trendline to guide the eye. 


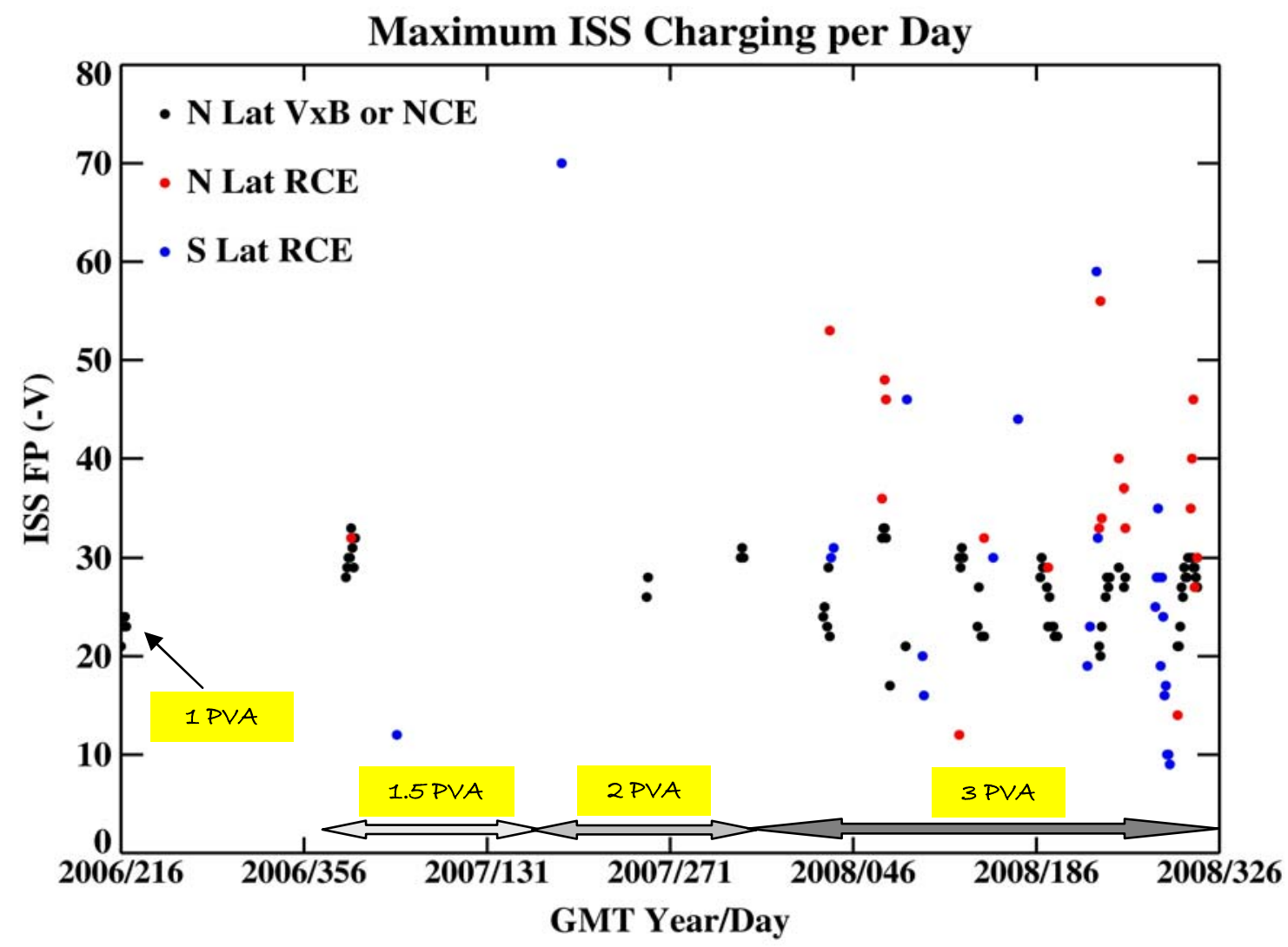

Figure 11: History of maximum charging of ISS per day based on FPMU measurements. The data are from days where no PCU operation occurred. The rapid charging event (RCE) data is separated from the normal charging event (NCE) data. For the FPMU location on the truss and the $+\mathrm{XVV}$ flight attitude, only northern hemisphere eclipse exit are shown for the NCE . 


\section{Survey of International Space Station Charging}

\section{Events}

P. D. Craven

NASA/Marshall Space Flight Center

Kenneth H. Wright, Jr.

University of Alabama-Huntsville

Joseph I. Minow, Victoria N. Coffey, Todd A. Schneider, Jason A. Vaughn, Dale C. Ferguson

NASA/Marshall Space Flight Center

Linda N. Parker

Jacobs Technology

UAHuntsville

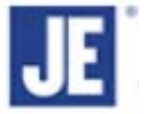


$>$ A survey of the charging measured by the Floating Potential Measurement Unit (FPMU), mounted on the International Space Station (ISS), has been performed.

$>$ The FPMU measures the ISS floating potential as well as the density and temperature of the plasma environment.

$>$ The FPMU was installed in August 2006 and has been operated since then during intermittent data campaigns. 


\section{Floating Potential Measurement Unit (FPMU)}

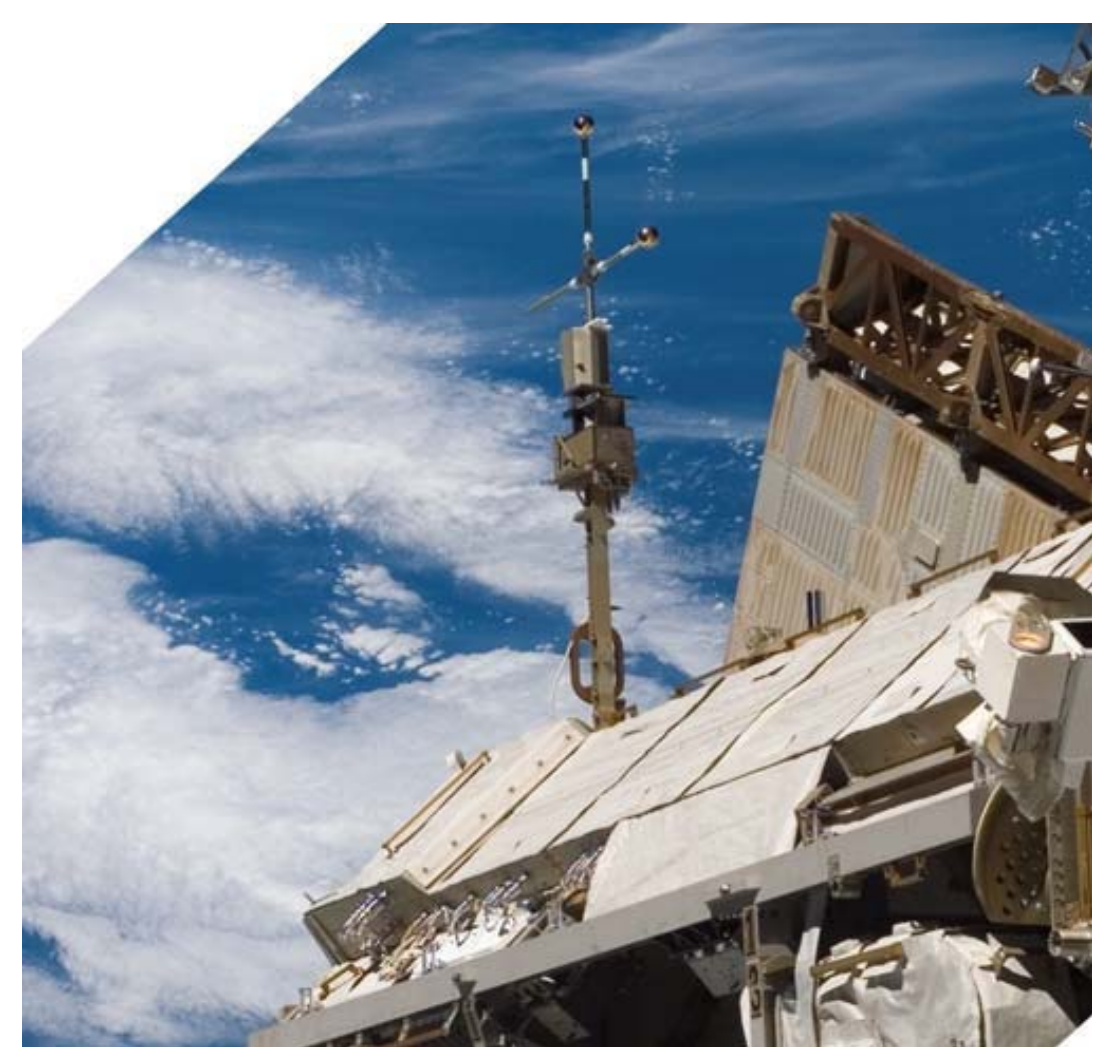
FPP: Floating Potential Probe
WLP: Wide-sweep Langmuir Probe
NLP: Narrow-sweep Langmuir Probe
PIP: Plasma Impedance Probe

\begin{tabular}{|c|c|c|c|}
\hline Sensor & $\begin{array}{l}\text { Measured } \\
\text { Parameter }\end{array}$ & Rate $(\mathrm{Hz})$ & Effective Range \\
\hline FPP & $v_{F}$ & 128 & $-180 V$ to $+180 V$ \\
\hline$W L P$ & $\begin{array}{l}N \\
T_{e} \\
V_{F}\end{array}$ & 1 & $\begin{array}{c}10^{9} \mathrm{~m}^{-3} \text { to } 5 \cdot 10^{12} \mathrm{~m}^{-3} \\
500 \mathrm{~K} \text { to } 10,000 \mathrm{~K} \\
-20 \mathrm{~V} \text { to } 80 \mathrm{~V}\end{array}$ \\
\hline NLP & $\begin{array}{l}N \\
T_{e} \\
V_{F}\end{array}$ & 1 & $\begin{array}{c}10^{9} \mathrm{~m}^{-3} \text { to } 5 \cdot 10^{12} \mathrm{~m}^{-3} \\
500 \mathrm{~K} \text { to } 10,000 \mathrm{~K} \\
-180 \mathrm{~V} \text { to }+180 \mathrm{~V}\end{array}$ \\
\hline PIP & $N$ & 1 & $1.1 \cdot 10^{10} \mathrm{~m}^{-3}$ to $4 \cdot 10^{12} \mathrm{~m}^{-3}$ \\
\hline
\end{tabular}




\section{$>167$ total days of FPMU operation}

$>$ Solar cycle in trailing minimum of cycle 23

$>$ Data periods dominated by low Kp (<3)

- FPMU data included in survey if:

$\checkmark$ Plasma Contactor Units are off.

$\checkmark$ Attitude of ISS is +XVV.

$\checkmark$ Data meets quality tests.

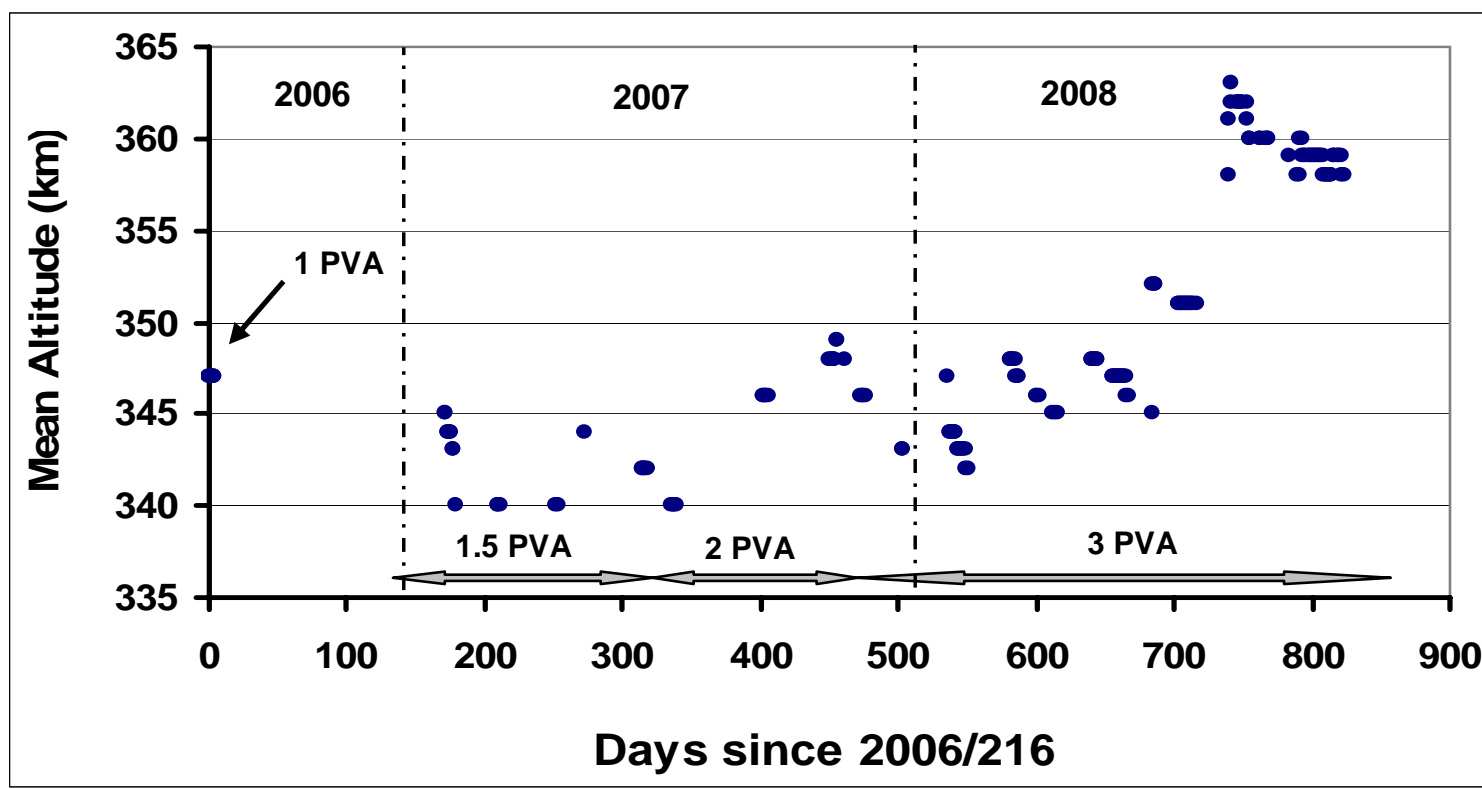




\section{Basic Charging Types for ISS}

$>$ Magnetic Induction

$>$ PV array plus Environment

$\checkmark$ Eclipse exit Normal Charging Event

$\checkmark$ Equatorial

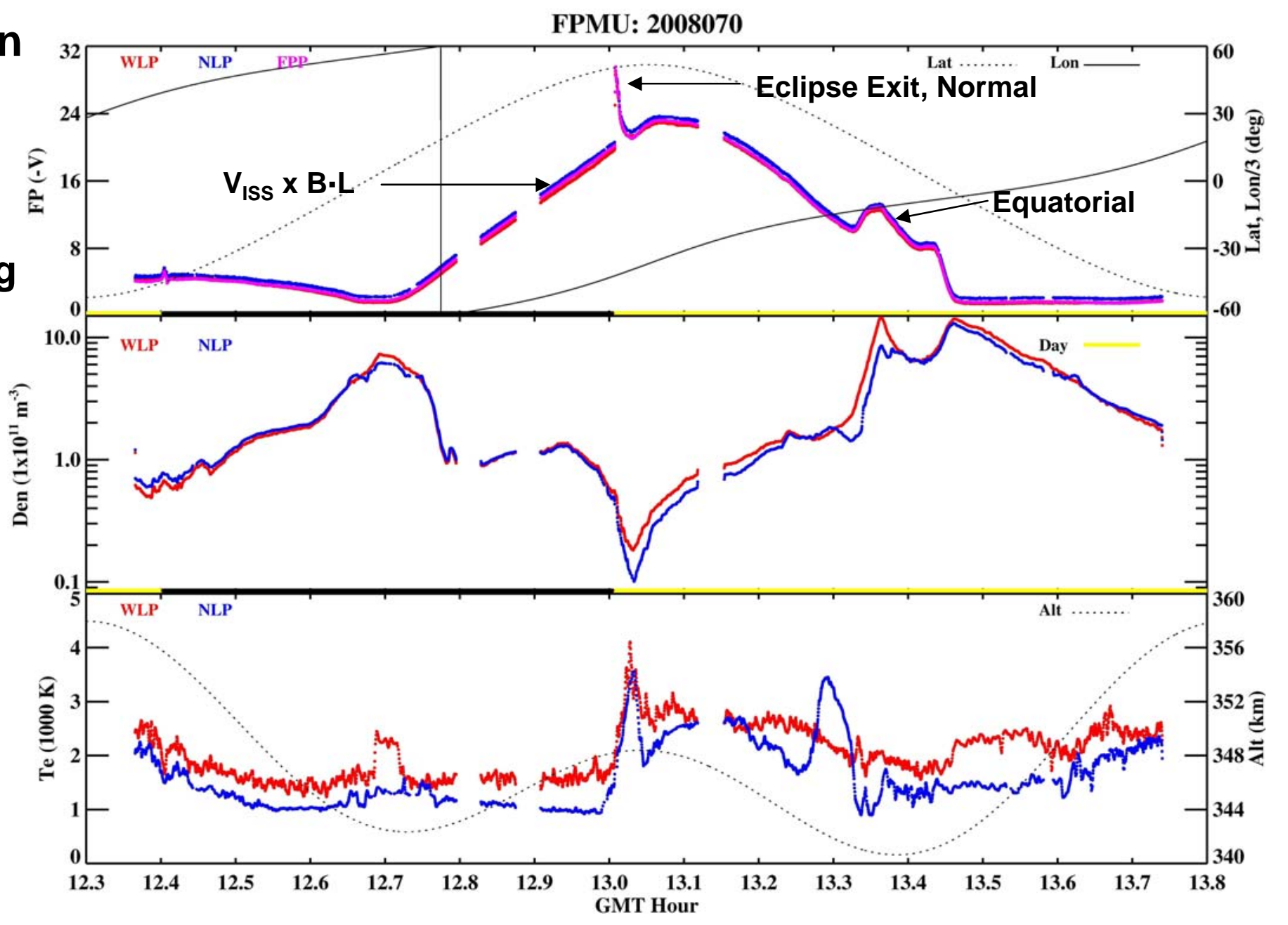




\section{Other Charging : Environment Only}

\section{High latitude - nighttime (Auroral charging)}
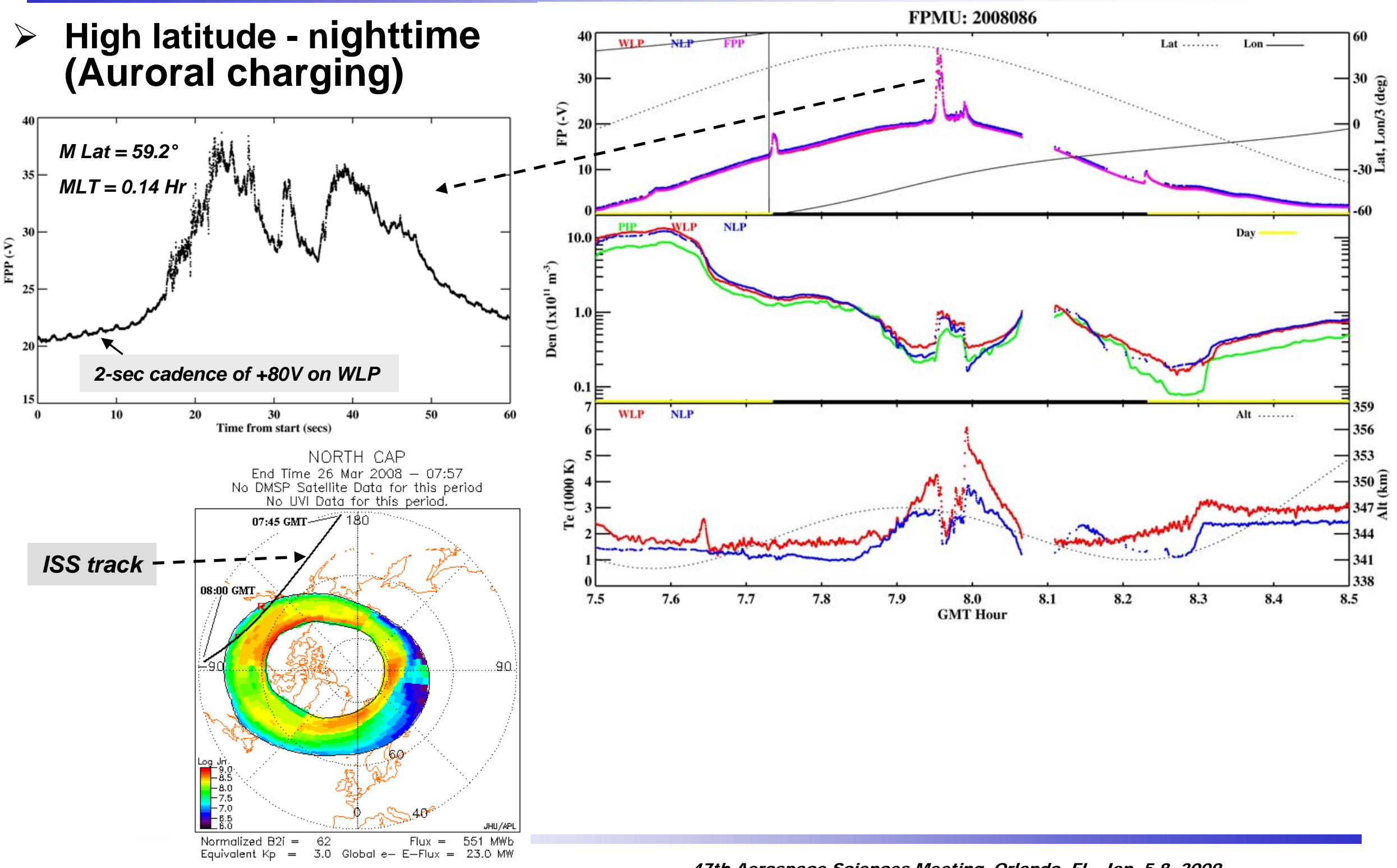


\section{Other Charging : Active Device}

\section{$>$ Operation of}

Plasma Electron Gun Payload (PLEGPAY)

\section{European} Plasma Contactor

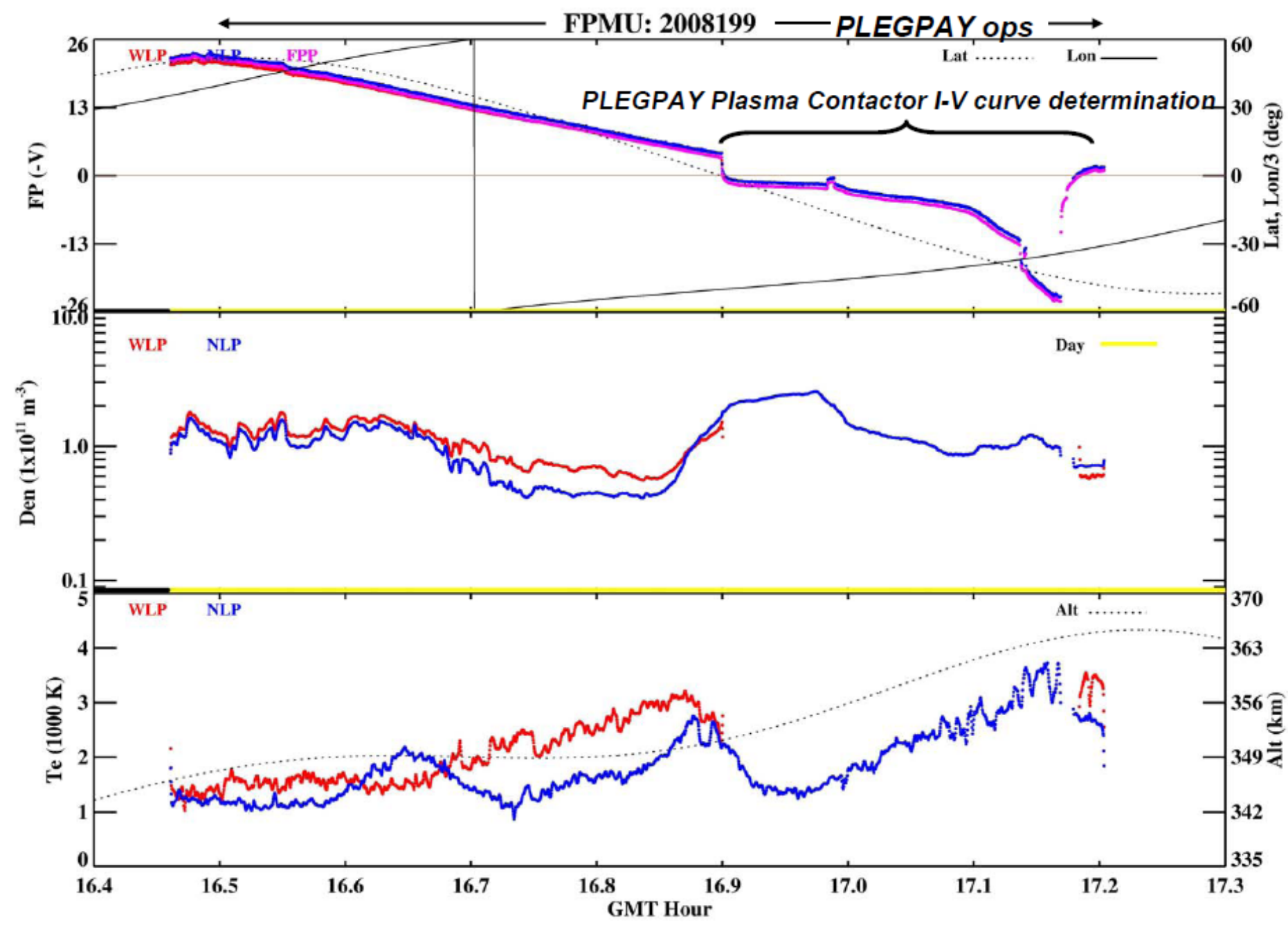


Timing aspects

- Rise Time: 10 s of seconds

- Trailing edge: several minutes - governed by array string management, plasma environment, and array attitude

Correlated with PVA response

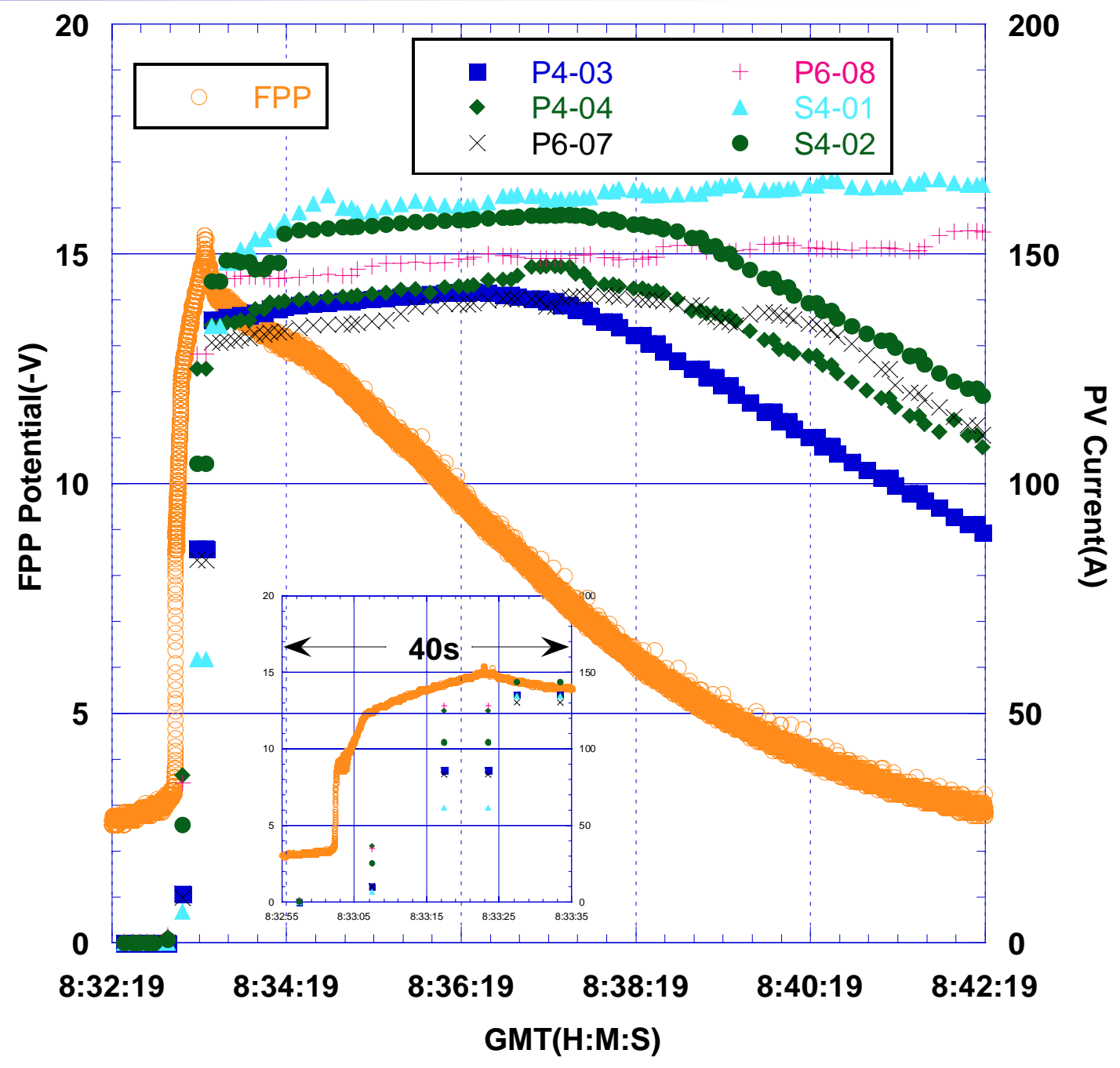


Eclipse Exit - Rapid Charging Event (RCE)

$>$ Timing aspects

- Rise Time: 2-5 s

- Trailing edge: 10-30 s

$>$ Not correlated with PVA response

$>$ More than 80 events observed

- Occurrence most likely when $\mathrm{N}<3.5 \times 10^{10} \mathrm{~m}^{-3}$

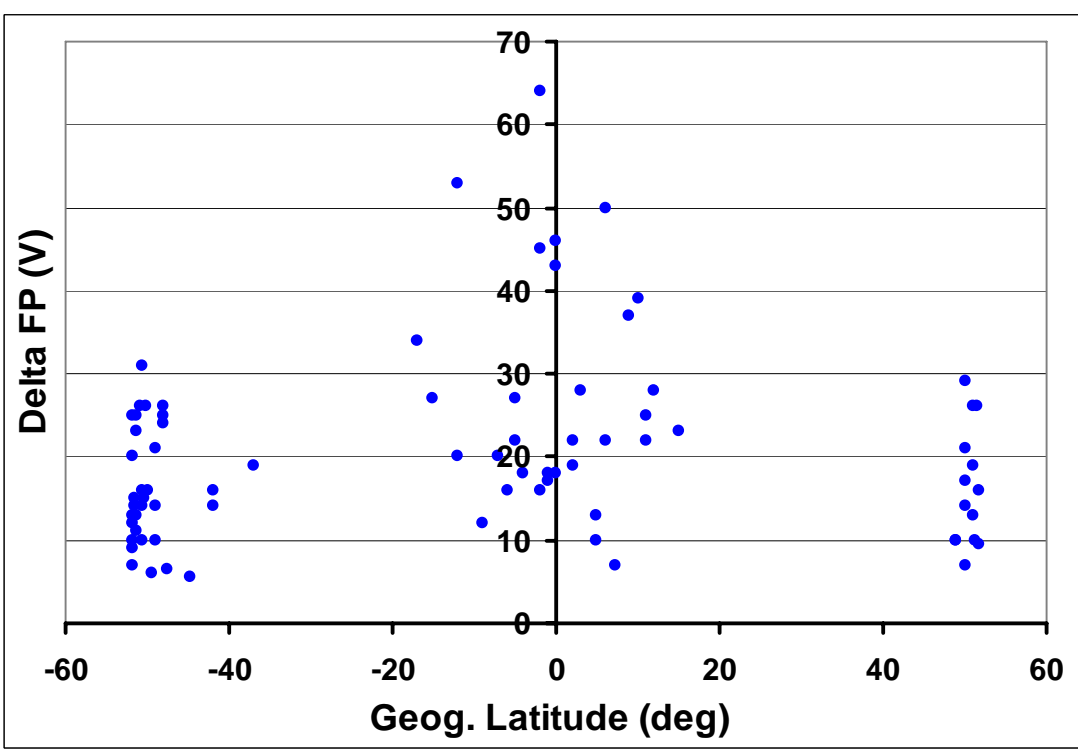

RCE for 2007188

07:20:33-07:23:33GMT

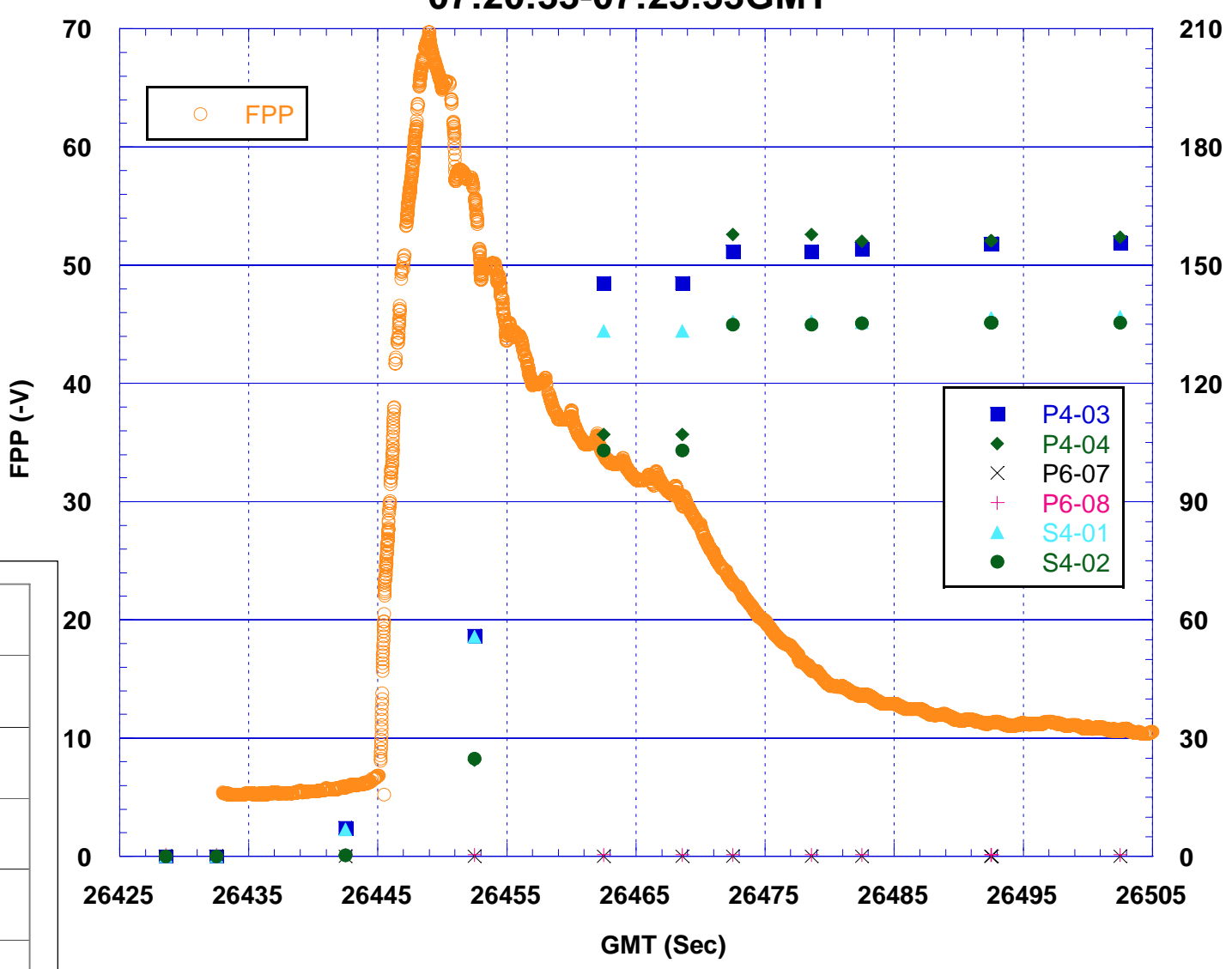

This is the largest amplitude RCE observed to date! 
RCE : Potential - Density relation

$>$ Appears to be a clear upper limit

$>$ Data scatter indicate other variables involved

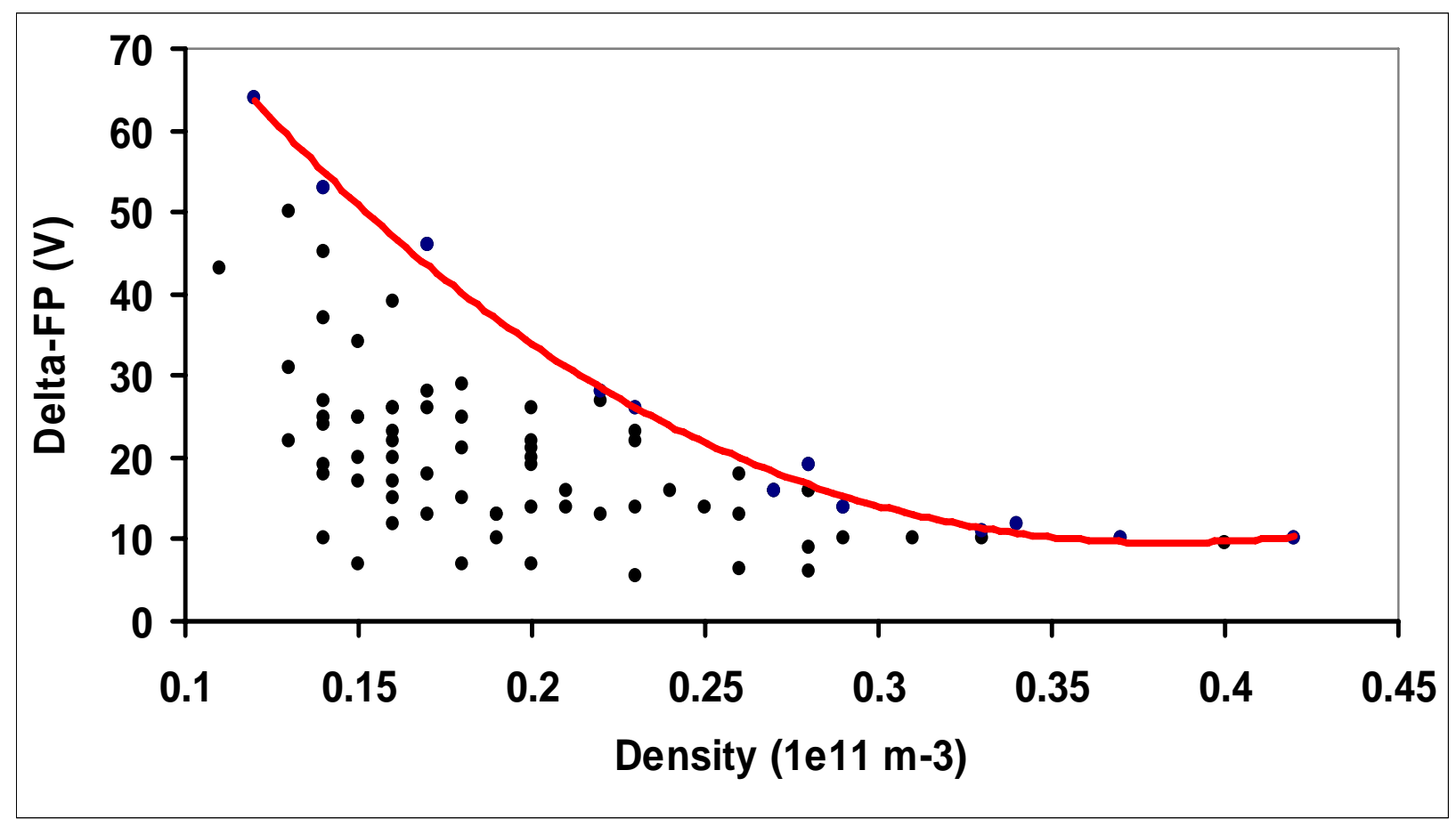


Time History: Maximum Potential per Day

$>$ No definitive increase in charging magnitude as PVA area increases.

$>$ Reasons:

$\checkmark$ S4 array not fully tracking

$\checkmark$ Extended Solar Min

$\checkmark$ ISS at higher altitude

Maximum ISS Charging per Day

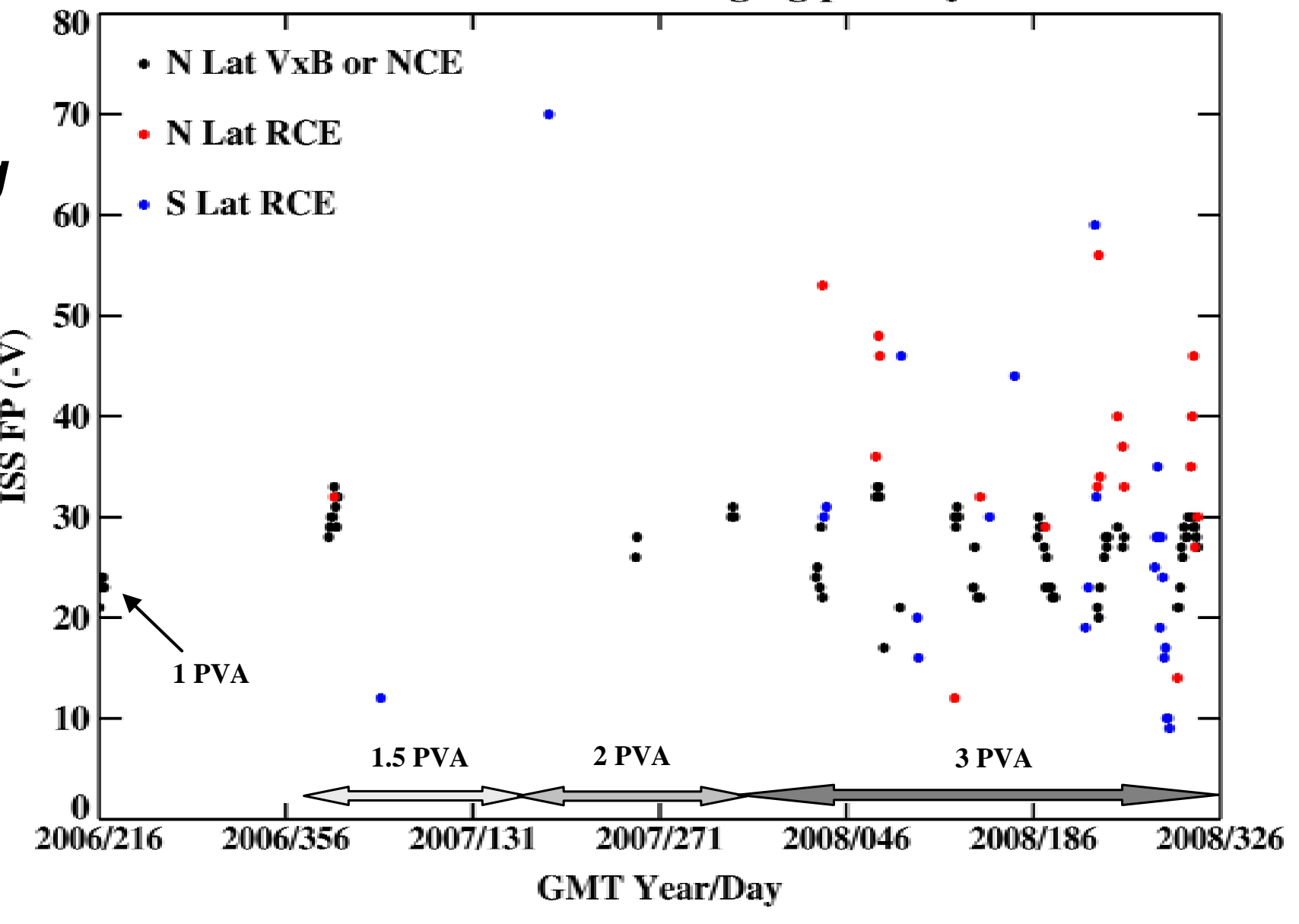

Although RCE occurrence appears to increase with PVA area, the disparity in sampling between pre-2008 and 2008 prevents any meaningful statement. 


\section{Summary}

$>$ Survey of Charging of the International Space Station

$\checkmark$ Data source: FPMU

$\checkmark 167$ days spread non-uniformly over $2+$ years.

$\checkmark$ ISS configuration changes include: from 1 PVA to 3 PVAs; Columbus, Kibo

$>$ Charging observations: 5 types ordered into 4 categories

$\checkmark$ Magnetic induction

$\checkmark$ Environment driven:

High latitude nighttime (Auroral)

$\checkmark$ Actively Driven

Plasma contactors (PLEGPAY) 
Summary (cont.)

$\checkmark$ Photo-Voltaic Array driven

Equatorial

Eclipse entrance

Eclipse exit: Normal; Rapid - New Discovery

$>$ Maximum amplitude Rapid Charging Event to date has reached $70 \mathrm{~V}$.

$\checkmark$ While this charging level is somewhat high, the duration of the event is too short to pose a dielectric breakdown threat to external surface coatings. 


\section{Backup Charts}




\section{RCE : Trailing Edge Time Constant}

\section{Trailing edge fit with stretched exponential: $A \cdot \exp (-t / t a u)+B \cdot[1-\exp (-t / t a u)]$}
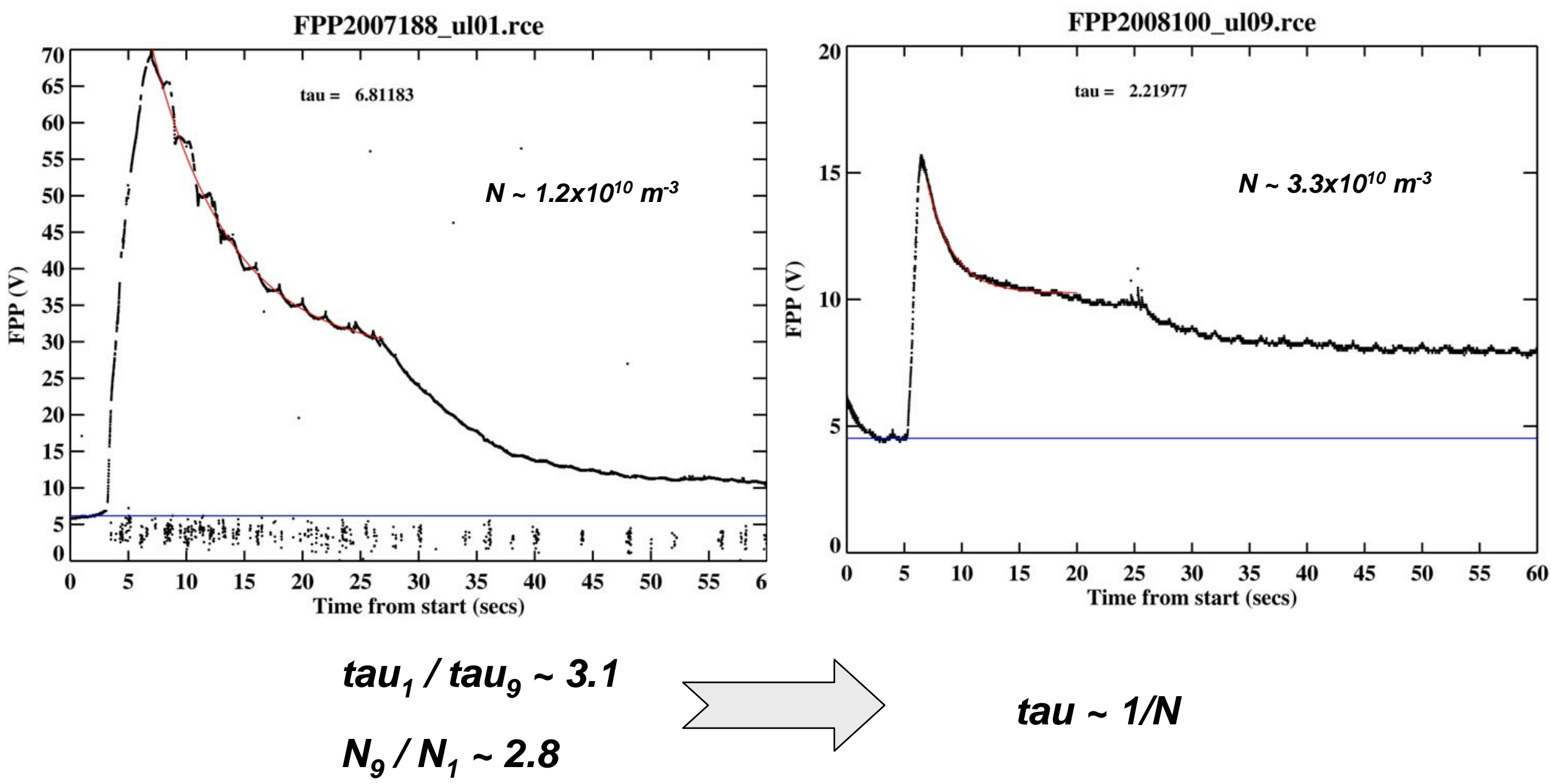